\title{
Metallocene-catalyzed ethylene- $\alpha$-olefin isomeric copolymerization: A perspective from hydrodynamic boundary layer mass transfer and design of MAO anion
}

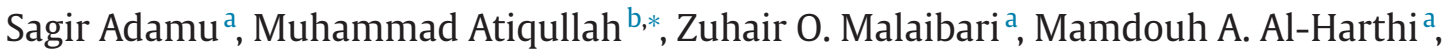 \\ Abdul-Hamid M. Emwas ${ }^{c}$, Anwar Ul-Hamid ${ }^{\mathrm{d}}$ \\ a Department of Chemical Engineering, King Fahd University of Petroleum E Minerals, Dhahran 31261, Saudi Arabia \\ ${ }^{\mathrm{b}}$ Center for Refining and Petrochemicals, Research Institute, King Fahd University of Petroleum E Minerals, Dhahran 31261, Saudi Arabia \\ ${ }^{c}$ NMR Core Laboratory, King Abdullah University of Science E' Technology, Thuwal 23955-6900, Saudi Arabia \\ ${ }^{\mathrm{d}}$ Center for Engineering Research, Research Institute, King Fahd University of Petroleum E Minerals, Dhahran 31261, Saudi Arabia
}

\section{A R T I C L E I N F O}

\section{Article history:}

Received 1 August 2015

Revised 16 September 2015

Accepted 20 October 2015

Available online xxx

\section{Keywords:}

Metallocene catalyst

Pseudo-homogeneous and in-situ

heterogeneous isomeric ethylene- $\alpha$-olefin copolymerization

Hydrodynamic boundary layer mass transfer Inter- and intra-chain backbone composition distribution

Lamellar thickness distribution

Thermal properties

\begin{abstract}
A B S T R A C T
This study reports a novel conceptual framework that can be easily experimented to evaluate the effects of hydrodynamic boundary layer mass transfer, methylaluminoxane (MAO) anion design, and comonomer steric hindrance on metallocene-catalyzed ethylene polymerization. This approach was illustrated by conducting homo- and isomeric copolymerization of ethylene with 1-hexene and 4-methyl-1-pentene in the presence of bis( $n$-butylcyclopentadienyl) zirconium dichloride $\left({ }^{\mathrm{n}} \mathrm{BuCp}\right)_{2} \mathrm{ZrCl}_{2}$, using (i) MAO anion 1 (unsupported $\left[\mathrm{MAOCl}_{2}\right]^{-}$) and pseudo-homogeneous reference polymerization, and (ii) MAO anion 2 (supported $\mathrm{Si}-\mathrm{O}-\left[\mathrm{MAOCl}_{2}\right]^{-}$) and in-situ heterogeneous polymerization. The measured polymer morphology, catalyst productivity, molecular weight distribution, and inter-chain composition distribution were related to the locus of polymerization, comonomer effect, in-situ chain transfer process, and micromixing effect, respectively. The peak melting and crystallization temperatures and \%crystallinity were mathematically correlated to the parameters of microstructural composition distributions, melt fractionation temperatures, and average lamellar thickness. These relations showed to be insightful. The comonomer-induced enchainment defects and the eventual partial disruption of the crystal lattice were successfully modeled using Flory and GibbsThompson equations. The present methodology can also be applied to study ethylene- $\alpha$-olefin copolymerization, performed using MAO-activated non-metallocene precatalysts.
\end{abstract}

(c) 2015 Published by Elsevier B.V. on behalf of Taiwan Institute of Chemical Engineers.

\section{Introduction}

Olefin polymerization catalysts can be broadly classified as conventional Ziegler-Natta (Z-N), metallocene, post-metallocene, and late transition metal. Out of these four classes, metallocenes are capable of undergoing remarkable structural variations through modifications and substitutions in the cyclopentadienyl $\pi$-ligand, the central transition metal, and the related $\sigma$-ligands. Consequently, they can regulate the comonomer-introduced branch distribution, inter- and intra-chain microstructures, and structural/enchainment defects of ethylene- $\alpha$-olefin copolymers in a highly versatile fashion. Additionally, well-defined polyolefin microstructures that range from atactic to stereoregular and stereoblock poly( $\alpha$-olefins) can as well be synthesized. From a fundamental scientific viewpoint, our

\footnotetext{
* Corresponding authors. Tel.: +96613 8603898; fax: +966138604509.

E-mail addresses: matiq@kfupm.edu.sa (M. Atiqullah), zuhairom@kfupm.edu.sa (Z.O. Malaibari).
}

current knowledge, regarding the mechanism of olefin polymerization, and the precatalyst structure versus polymer backbone and property relation, therefore, exceeds what we knew before. In parallel, we observe that the yearly journal publications and review reports [1-8] keep on adding since early 1980 when metallocene serendipity was first published by Kamnisky and his research group. Because of the above advantages, aggressive research continues worldwide in metallocene-catalyzed olefin polymerization to make polyolefin a dynamic technology-driven industry.

Three types of polyolefin-producing industrial processes exist. These are solution, slurry, and gaseous fluid-bed. Out of these three, the latter two processes dominate the commercial production because of their competitive benefits [1-8]. Despite the advantages summarized above, metallocene-based industrial polyolefin processes are far less than the most-prevalent $\mathrm{Z}-\mathrm{N}$ ones.

Ethylene-4-methyl-1-pentene (E-4M1P) copolymers have a lot of applications in power, control, optical, telephone, and signal cables. BP’s Innovex ${ }^{\circledR}$ grades are selected examples of commercial E-4M1P 


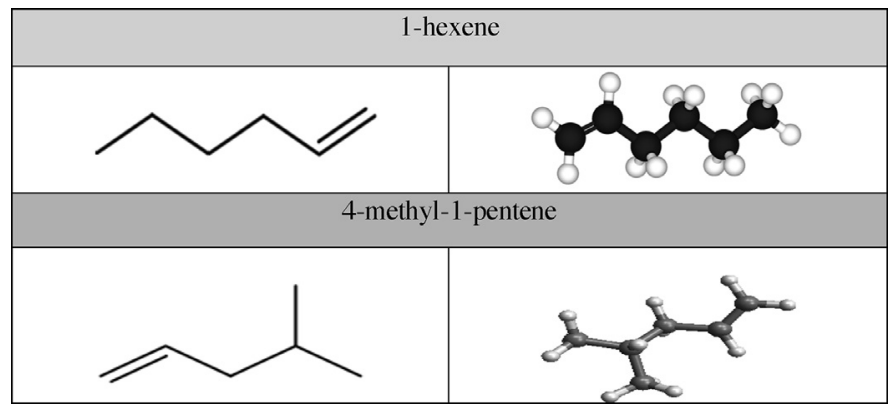

Fig. 1. Isomeric structures of 1-hexene and 4-methyl-1-pentene.

copolymers. Structurally, 1-hexene and 4M1P are isomers and the latter, unlike the former, is a sterically hindered $\alpha$-olefin (see Fig. 1). However, we note that the contributions to metallocene-catalyzed ethylene-1-hexene $(\mathrm{E}-1-\mathrm{H})$ copolymerization are far greater in the literature than those related to ethylene-4-methyl-1-pentene (E-4M1P) copolymerization. In E-4M1P copolymerization, the published metallocene research can be summarized as follows. Several groups worked on E-4M1P solution copolymerization to investigate catalyst structure-activity relationship, influence of polymerization conditions, comonomer effect, and copolymer microstructure (as appropriate) [9-15]. Awudza and Tait [16] show to be the only group that studied E-4M1P slurry copolymerization, using supported silica/MAO/Cp $\mathrm{ZrCl}_{2}$ catalyst, where $\mathrm{MAO}$ and $\mathrm{Cp}_{2} \mathrm{ZrCl}_{2}$ stand for methyl aluminoxane and bis(cyclopentadienyl) zirconium dichloride, respectively. They primarily investigated comonomer effect.

Reactor fouling, thermal runaway, poor polymer morphology, etc. are several major problems of a typical metallocene-catalyzed solution olefin polymerization. None of the above studies addressed these problems; they were rather more basic than applied. Also, the synthesis of $\mathrm{E}-1-\mathrm{H}$ versus E-4M1P copolymers was not compared from a common isomeric copolymerization viewpoint. Hence, process developmental applied and engineering research in metallocenecatalyzed E-4M1P copolymerization should be paid more attention. This is the motivation behind this study. However, we would like to remain focused. Therefore, we aim at developing a novel general conceptual framework that can be easily experimented to evaluate the effects of the following three factors-hydrodynamic boundary layer (HBL), MAO anion design, and comonomer steric hindranceon metallocene-catalyzed ethylene polymerization, including catalyst productivity, polymerization mechanism, comonomer and segregation effects, copolymer composition distribution, polymer microstructure, and thermal behavior.
We shall apply, in this regard, the concepts of pseudohomogeneous polymerization (developed in our laboratory) and insitu heterogeneous polymerization. The in-situ polymerization was originally conceived and published in 2000 by Soares et al. [17,18]. Both approaches will be applied to overcome the above-listed problems and ensure approximately comparable hydrodynamics and macro-mixing (which are very important).

In pseudo-homogeneous polymerization, an equivalent amount of the dehydroxylated support, metallocene, and cocatalyst are instantaneously premixed, preferably in a common solvent such as toluene (density $=0.8623 \mathrm{~g} / \mathrm{mL}$ at $25^{\circ} \mathrm{C}$ ). Then the resulting mixture, monomer, and comonomer are immediately fed into the reactor containing the polymerization diluent, namely $n$-hexane (density $=0.6548 \mathrm{~g} / \mathrm{mL}$ at $25^{\circ} \mathrm{C}$ ). Toluene (an aromatic compound) and $n$-hexane (an aliphatic compound), because of density difference, are immiscible. Methyl aluminoxane (MAO)-the most widely used cocatalyst-is soluble in toluene and insoluble in $n$-hexane. Therefore, they are likely to form, strictly and theoretically speaking, a two-phase microemulsion that contains the active catalytic species, effecting the polymerization. Hence, the polymerization primarily occurs in this microemulsion phase because of very prompt premixing and the afore-said mode of reactor feeding, which are stringent prerequisites to the currently defined pseudo-homogeneous reference polymerization. Note that a typical solution polymerization excludes the support and uses miscible solvent(s) for the metallocene, cocatalyst, and polymerization. Therefore, this is a limiting case of pseudo-homogeneous polymerization. On the other hand, in in-situ heterogeneous polymerization, ethylene, comonomer (1-hexene or 4-M1P), and metallocene first diffuse through a microemulsion hydrodynamic boundary layer (a mass transport barrier) of thickness $\delta$. Then they contact the cocatalyst-impregnated support which is the major locus of polymerization. Thus, the need for separately supporting metallocene before polymerization is eliminated. In the present context, the above hydrodynamic boundary layer (HBL) means a thin liquid layer that exists, due to the solid-liquid interactive forces, at the interface of the cocatalyst-impregnated support particles and the vigorously stirred microemulsion transport fluid [19] (see Fig. 2).

We shall use the following two differing anions, unsupported $\left[\mathrm{MAOCl}_{2}\right]^{-}$and supported $\mathrm{Si}-\mathrm{O}-\left[\mathrm{MAOCl}_{2}\right]^{-}$, the synthesis of which has been illustrated through Scheme 1 that shows the major relevant reactions $[6,20]$. Note that the variation in the design of novel co-catalyst anions, which is much easier and less costly than synthesizing new metallocenes, widens the scope of industrial process development.

To the best of our knowledge, the subject we propose to pursue has not been investigated before. Hence, we study this, which will

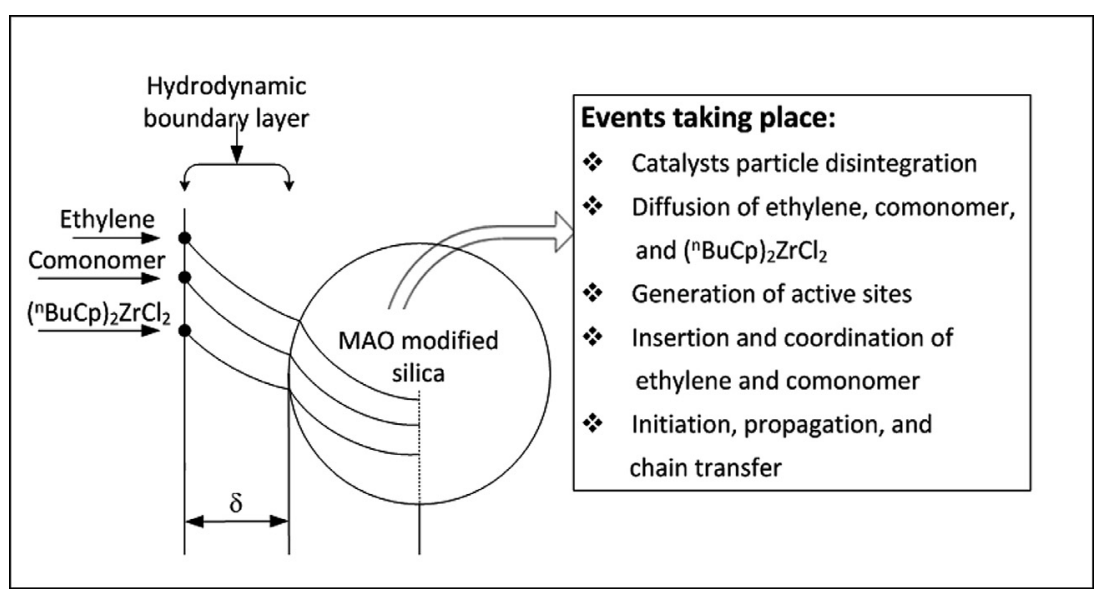

Fig. 2. In-situ heterogeneous polymerization and events taking place therein. 


$$
\begin{aligned}
\mathrm{MAO}+\left({ }^{\mathrm{n}} \mathrm{BuCp}\right)_{2} \mathrm{ZrCl}_{2} \rightarrow & {\left[\left({ }^{\mathrm{n}} \mathrm{BuCp}\right){ }_{2} \mathrm{ZrMe}\right]^{+}\left[\mathrm{MAOCl}_{2}\right]^{-} } \\
& \text {Pseudo-homogeneous reference polymerization } \\
\mathrm{Si}-\mathrm{OH}(\text { silica })+\mathrm{MAO} \rightarrow & \mathrm{Si}-\mathrm{O}-\mathrm{MAO}+\mathrm{CH}_{4} \uparrow \\
\mathrm{Si}-\mathrm{O}-\mathrm{MAO}+\left({ }^{\mathrm{n}} \mathrm{BuCp}\right)_{2} \mathrm{ZrCl}_{2} \rightarrow & {\left[\left({ }^{\mathrm{n}} \mathrm{BuCp}\right)_{2} \mathrm{ZrMe}\right]^{+} \mathrm{Si}-\mathrm{O}-\left[\mathrm{MAOCl}_{2}\right]^{-} } \\
& \text {In-situ heterogeneous polymerization }
\end{aligned}
$$

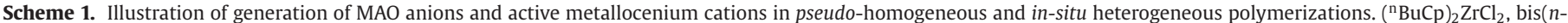
butyl cyclopentadienyl) zirconium dichloride, is an aspecific $C_{2 v}$-symmetric metallocene; this is very stable and commercially widely available.

hopefully add new insight to metallocene-catalyzed olefin polymerization and broaden our comprehension.

\section{Experimental}

\subsection{Materials}

Silica PQ 3030 having surface area of $322 \mathrm{~m}^{2} / \mathrm{g}$, an average pore volume of $3.00 \mathrm{~cm}^{3} / \mathrm{g}$, and a pore size of $374 \AA$ was used as the cocatalyst support.

$\left({ }^{\mathrm{n}} \mathrm{BuCp}\right)_{2} \mathrm{ZrCl}_{2}$ and MAO (30 wt\% in toluene) were bought from Chemtura, Germany. Analytical grade toluene, $n$-hexane (both 99.999\% pure), molecular sieves, 0.05 w/v\% 2,6-di-tert-butyl4-methyl phenol (BHT), 1,2,4 trichlorobenzene (TCB) (analytical grade and deuterated), triisobutylaluminum (TIBA), and 4-methyl-1pentene (4M1P)-all were purchased from Sigma-Aldrich. Ethylene (99.999\% pure) was procured from a local vendor; and oxygen trap (OT-4-SS) and moisture absorber (500CC 316-SS), from Agilent and Parker, respectively. United Petrochemicals, an affiliate of Saudi Basic Industries Corporation (SABIC), gifted 1-hexene.

\subsection{Synthesis of MAO-impregnated silica}

The MAO-impregnated silica was synthesized as follows by doing all the manipulations under argon using standard Schlenk technique.

The required amount of silica was dehydroxylated at $250{ }^{\circ} \mathrm{C}$ for $4 \mathrm{~h}$ using a Thermocraft furnace equipped with a vertical quartz glass tube, a digital temperature indicator and a controller, a gas flow meter, and a vacuum pump. The silica was continuously fluidized during dehydroxylation using nitrogen. Upon dehydroxylation, it was stored in an inert glove box.

Toluene was dried using 4A activated molecular sieve. The required amounts of dehydroxylated silica and the dried toluene were slurried in a specially designed Schlenk flask. The calculated volume of MAO was added to this slurry drop by drop under argon using constant stirring at room temperature. Then this was heated for several hours for complete impregnation. The resulting product was dried under vacuum. The dry free-flowing MAO-impregnated silica was saved in a glove box.

\subsection{Polymerization trials}

Ethylene was homo- and copolymerized using a computerinterfaced, AP Miniplant laboratory-scale reactor set up. It consists of a fixed top head and a one-liter jacketed Büchi glass autoclave. The glass reactor was baked for $2 \mathrm{~h}$ at $120^{\circ} \mathrm{C}$. Then, it was purged with nitrogen four times at the same temperature. The reactor was cooled from $120^{\circ} \mathrm{C}$ to $40^{\circ} \mathrm{C}$. About $200 \mathrm{~mL}$ of dried $n$-hexane was transferred to the reactor. Then, $1.0 \mathrm{~mL}$ of $1.0 \mathrm{M}$ triisobutylaluminum (TIBA) was added to scavenge the impurities that may poison the catalyst, and the mixture was stirred for 10 min. $n$-hexane was dried by contacting it with $4 \mathrm{~A}$ molecular sieves at room temperature over night that decreased the moisture level to less than $10 \mathrm{ppm}$. The molecular sieve was activated at $230^{\circ} \mathrm{C}$. At this stage, for the copolymerization, $15 \mathrm{~mL}$ 1-hexene or 4M1P was added. The resulting mixture was stirred at $50 \mathrm{rpm}$ for $10 \mathrm{~min}$. For the homopolymerization, no 1-hexene or 4M1P was used.

The in-situ heterogeneous polymerization was conducted as follows. An estimated amount of MAO-supported silica was slurried in $50 \mathrm{~mL}$ of $n$-hexane. The whole volume was siphoned into the reactor under mild argon flow. On the other hand, a solution of ( $\left.{ }^{\mathrm{n}} \mathrm{BuCp}\right)_{2} \mathrm{ZrCl}_{2}$ in toluene, that corresponded to an $\mathrm{Al}: \mathrm{Zr}$ molar ratio of about 50 , was added to the reactor. Ethylene was passed through oxygen- and moisture-removing columns. Then it was fed into the reactor at a constant flow rate of $5000 \mathrm{NmL} / \mathrm{min}$. The polymerization temperature and stirrer speed were set at $50{ }^{\circ} \mathrm{C}$ and $400 \mathrm{rpm}$, respectively. An anchor stirrer (impeller) was used. The trial was continued for $1 \mathrm{~h}$. The polymerization was terminated by closing the ethylene flow and venting the post-polymerization ethylene (in the reactor) to the atmosphere. Then, the data acquisition was stopped; the stirrer speed was reduced to about $100 \mathrm{rpm}$; and the reactor was gradually cooled to room temperature.

During pseudo-homogeneous reference polymerization, the above amounts of silica, MAO, and $\left({ }^{\mathrm{n}} \mathrm{BuCp}\right)_{2} \mathrm{ZrCl}_{2}$ were first instantaneously pre-contacted in dried toluene. Note that toluene is a common solvent for $\mathrm{MAO}$ and $\left({ }^{\mathrm{n}} \mathrm{BuCp}\right)_{2} \mathrm{ZrCl}_{2}$. Then the resulting mixture, ethylene, and the experimental $\alpha$-olefin comonomer were immediately introduced to the reactor. The rest of the above procedures were repeated.

After conducting the polymerization trials as described above, the reactor was opened; the resulting polyethylene was dried under ambient conditions in a hood, and the dried polymer was weighed to determine the yield. The polymer yield was subsequently used to determine the corresponding catalyst productivity which has been reported in Table 1 . Using each polymerization mode (pseudo-homogeneous and in-situ heterogeneous), one homo- and two copolymers were prepared.

\subsection{Polymer particulate surface morphology}

The experimental polyethylene samples were first coated with a layer of carbon to increase the surface conductivity. These coated samples were characterized using a scanning electron microscope (SEM) equipped with an energy dispersive X-ray spectrometer (EDS). The particulate morphology was probed by operating the electron microscope in the backscattered electron imaging (BEI) mode.

\subsection{Molecular weights and polydispersity indices}

The synthesized polyethylenes were characterized in terms of molecular properties [weight average molecular weight $\left(M_{W}\right)$ and polydispersity index (PDI)] using a Waters 200 gel permeation chromatography (GPC) instrument. The column temperature was set at $135{ }^{\circ} \mathrm{C}$. Polyethylene sample (about $1.0 \mathrm{mg}$ ), taken in a $1 \mathrm{~mL}$ vial, was dissolved in $1.0 \mathrm{~mL}$ Santanox R-stabilized 1,2,4 trichlorobenzene (TCB) as follows. The vial was shaken in the warming compartment of the GPC instrument at $135^{\circ} \mathrm{C}$ for about $5 \mathrm{~h}$ to completely dissolve the sample. 
Table 1

Catalyst productivity and summary of as-synthesized polyethylene properties.

\begin{tabular}{|c|c|c|c|c|c|c|}
\hline \multirow[t]{2}{*}{$\begin{array}{l}\text { Catalyst productivity } \\
\text { and polyethylene } \\
\text { properties }\end{array}$} & \multicolumn{3}{|c|}{$\begin{array}{l}\text { MAO anion 1: unsupported } \\
{\left[\mathrm{MAOCl}_{2}\right]^{-} \text {Pseudo-homogeneous }} \\
\text { polymerization }\end{array}$} & \multicolumn{3}{|c|}{$\begin{array}{l}\text { MAO anion 2: silica-supported } \\
\text { bulkier } \mathrm{Si}-\mathrm{O}-\left[\mathrm{MAOCl}_{2}\right]^{-} \mathrm{In} \text {-situ } \\
\text { heterogeneous polymerization }\end{array}$} \\
\hline & $\begin{array}{l}\text { Ethylene } \\
\text { homopolymer }\end{array}$ & $\begin{array}{l}\text { E-1-hexene } \\
\text { copolymer }\end{array}$ & $\begin{array}{l}\text { E-4M1P } \\
\text { copolymer }\end{array}$ & $\begin{array}{l}\text { Ethylene } \\
\text { homopolymer }\end{array}$ & $\begin{array}{l}\text { E-1-hexene } \\
\text { copolymer }\end{array}$ & $\begin{array}{l}\text { E-4M1P } \\
\text { copolymer }\end{array}$ \\
\hline Catalyst productivity (g PE/g cat hr) & 60.00 & 116.36 & 110.91 & 46.36 & 67.00 & 61.50 \\
\hline$M_{w}(\mathrm{~g} / \mathrm{mol})$ & 329,664 & 291,092 & 181,811 & 318,574 & 229,051 & 255,864 \\
\hline$\Delta M_{w}(\%)$ & 0.00 & 11.70 & 44.85 & 0.00 & 28.10 & 19.68 \\
\hline Polydispersity index $(\mathrm{PDI})^{\S}$ & 1.43 & 2.42 & 2.61 & 1.58 & 2.51 & 2.22 \\
\hline Peak melting point $T_{p m}\left({ }^{\circ} \mathrm{C}\right)$ & 133.93 & 114.97 & 118.01 & 134.08 & 114.08 & 120.14 \\
\hline Peak crystallization point $T_{p c}\left({ }^{\circ} \mathrm{C}\right)$ & 116.76 & 100.25 & 104.06 & 117.36 & 100.66 & 106.82 \\
\hline DSC crystallinity $X_{c}(\%)$ & 58.29 & 35.87 & 44.53 & 65.70 & 41.92 & 43.44 \\
\hline WAXRD crystallinity ${ }^{\dagger} X_{c}(\%)$ & 55.45 & 34.38 & 42.52 & 62.41 & 40.07 & 41.49 \\
\hline$\Delta T_{p m}\left({ }^{\circ} \mathrm{C}\right)$ & 0.00 & 18.96 & 15.92 & 0.00 & 20.00 & 13.67 \\
\hline$\Delta T_{p c}\left({ }^{\circ} \mathrm{C}\right)$ & 0.00 & 16.51 & 12.7 & 0.00 & 16.70 & 10.54 \\
\hline$\Delta X_{c}(\%)$ & 0.00 & 22.42 & 18.76 & 0.00 & 23.78 & 22.26 \\
\hline Polymer material density $\rho_{\text {polym }}\left(\mathrm{g} / \mathrm{cm}^{3}\right)$ & 0.935 & 0.902 & 0.914 & 0.947 & 0.900 & 0.913 \\
\hline Weight average lamellar thickness $L_{\text {wav DSC GT }}(\mathrm{nm})$ & 20.53 & 7.90 & 9.45 & 20.72 & 8.04 & 9.96 \\
\hline Most probable lamellar thickness $L_{M P D S C} G T(\mathrm{~nm})$ & 21.13 & 9.27 & 10.64 & 21.47 & 9.07 & 11.60 \\
\hline Variance $\sigma_{\text {lamellar thickness }}(\mathrm{nm})$ & 7.93 & 2.48 & 3.03 & 4.44 & 2.56 & 3.02 \\
\hline Weight average lamellar thickness $L_{\text {wav SSA DSC }}(\mathrm{nm})$ & Does not apply. & 7.91 & 9.55 & Does not apply. & 7.93 & 10.64 \\
\hline Variance $\sigma_{\text {lamellar SSA }}(\mathrm{nm})$ & Does not apply. & 2.00 & 2.84 & Does not apply. & 2.22 & 3.11 \\
\hline Crystaf soluble fractions & Does not apply. & 0.0004 & 0.0005 & Does not apply. & 0.0014 & 0.0000 \\
\hline$T_{\sigma \text { Crystaf }}\left({ }^{\circ} \mathrm{C}\right)$ & Does not apply. & 9.56 & 7.43 & Does not apply. & 11.51 & 6.72 \\
\hline
\end{tabular}

$\mathrm{PE}=$ Ethylene homo- and copolymer.

$L_{\text {wav SSA DSC }}=1.2866 \times L_{\text {wav DSC GT }}-2.3631 ; R^{2}=0.9703$. $L_{\text {wav DSC GT }}=0.9584 \times L_{\text {MPDSC GT }}+1.663 ; R^{2}=0.9976$.

$\S$ PDI reports the deviation of the molecular weight distribution (MWD) from a situation where all the as-synthesized chains are of equal length, that is, $\mathrm{PDI}=1$. As the MWD broadens, the PDI exceeds 1. PDI does not represent the breadth of MWD.

$\dagger$ Determined applying the correlation $X_{C \text { WAXRD }}=0.9396 \times X_{c D S C}+0.6779 ; R^{2}=0.9866$; WAXRD $=$ wide angle X-ray diffraction. This correlation was developed using the Table 1 data of Reference [21]. The results are comparable. However, $X_{c}$ WAXRD, being free of recrystallization effect, is a little lower than $X_{c D S C}$. In DSC, recrystallization effect is usually unavoidable.

Before injecting the samples, the differential refractive index (DRI) detector was purged for $4 \mathrm{~h}$ using TCB ( $1 \mathrm{~mL} / \mathrm{min}$ ) to obtain stable baseline. Also, the inlet pressure (IP) and the differential pressure (DP) outputs were purged for $1 \mathrm{~h}$. The flow rate of TCB was $1.0 \mathrm{~mL} / \mathrm{min}$ and each sample was analyzed for $35 \mathrm{~min}$.

The instrument was calibrated using nine polystyrene standards whose peak molecular weights ranged from 580 to 3.79 million. The polystyrene calibration curve was converted into the corresponding polyethylene calibration curve using the Mark-Houwink constants of both polymers [22]. Table 1 reports the measured average molecular weights and the polydispersity indices.

\subsection{Thermal properties, density, and copolymer melt fractionation}

The thermal properties of the as-synthesized polyethylenes were measured in terms of peak melting $\left(T_{p m}\right)$ and crystallization $\left(T_{p c}\right)$ temperatures, and \%crystallinity $\left(X_{C}\right)$ using a differential scanning calorimeter (DSC Q2000, Texas Instrument). The instrument was calibrated using indium. The experimental procedure reported in the literature was followed $[23,24]$. The data were acquired for each cycle and handled using the TA explorer software. The measured $X_{c}$ was subsequently used to calculate the polymer material density $\rho_{\text {polym }}$, following the rule of additivity of volumes of polyethylene amorphous and crystalline phases [25]: $X_{c}=\left(1 / \rho_{\text {polym }}-1 / \rho_{a}\right) /\left(1 / \rho_{c}-\right.$ $\left.1 / \rho_{a}\right)$; where $\rho=$ density; $a=$ amorphous phase; $c=$ crystalline phase; and polym = polymer. For polyethylene, $\rho_{c}=1.004 \mathrm{~g} / \mathrm{mL}$ and $\rho_{a}=0.853 \mathrm{~g} / \mathrm{mL}$. The \%crystallinity measured using DSC was also estimated applying the correlation $X_{C \text { WAXRD }}=0.9396 \times X_{C D S C}+0.6779$; $R^{2}=0.9866$; WAXRD = wide angle X-ray diffraction. This correlation was developed using the Table 1 data of Reference [21]. The results are comparable. Table 1 reports the above thermal properties and densities of the as-synthesized polyethylenes.

The synthesized copolymers were thermally fractionated using the above DSC instrument, and following the successive selfnucleation and annealing (SSA) experimental procedure reported in the literature [26-32]. Seven annealing steps $(160,125,119,114,111$ 107 , and $103^{\circ} \mathrm{C}$ ) were applied. Details are available in Reference [32].

\subsection{Copolymer composition distribution}

The composition distribution of the as-synthesized copolymers was determined using Polymer Char CRYSTAF 100 instrument. The fractionation principle of this technique is already published in the literature [33-35]. The sample solution of concentration $0.1 \%(\mathrm{w} / \mathrm{w})$ was prepared in $1,2,4$ trichlorobenzene (TCB) at $160{ }^{\circ} \mathrm{C}$ under stirring for $60 \mathrm{~min}$. The solution was equilibrated at $95{ }^{\circ} \mathrm{C}$ for $45 \mathrm{~min}$. This was subsequently crystallized at a cooling rate of $0.2^{\circ} \mathrm{C} / \mathrm{min}$ from 95 to $35^{\circ} \mathrm{C}$. The qualitative differential composition distribution $\left(\frac{d w}{d T}\right.$ versus $T$ ) was obtained by numerical differentiation of the integral analogue.

\subsection{Copolymer microstructure and Flory ethylene sequence length distribution}

The microstructural parameters, including average ethylene, 1hexene, and 4M1P mole\% in the synthesized copolymers, were determined using ${ }^{13} \mathrm{C}$ NMR spectroscopy. For this purpose, a Bruker 600 MHz AVANAC III spectrometer (Bruker BioSpin, Rheinstetten, Germany) was used. The details of this instrument and the NMR operating conditions and procedure are available in one of our earlier publications [24]. The spectra were recorded using DEPT (distortionless enhancement by polarization transfer) 135 pulse sequence, and they were analyzed applying Bruker Topspin 2.1 software (Bruker BioSpin, Rheinstetten, Germany). The receiver gain was set at 203. Exponential line broadening of $1 \mathrm{~Hz}$ was applied before Fourier transformation. DEPT was used because of its prioritized advantages that include enhanced ${ }^{13} \mathrm{C}$ signal sensitivity; superior spectral editing; and capability to distinguish methyl $\mathrm{CH}_{3}$, methylene $\mathrm{CH}_{2}$, and methine $\mathrm{CH}$ sites, and identify branches. 
Table 2

Comparison of microstructural parameters of the as-synthesized copolymers as a function of MAO anion types.

\begin{tabular}{|c|c|c|c|c|}
\hline \multirow[t]{2}{*}{ Copolymer microstructural properties } & \multicolumn{2}{|c|}{$\begin{array}{l}\text { MAO anion 1: unsupported } \\
{\left[\mathrm{MAOCl}_{2}\right]^{-} \text {Pseudo-homogeneous }} \\
\text { polymerization }\end{array}$} & \multicolumn{2}{|c|}{$\begin{array}{l}\text { MAO anion 2: silica-supported } \\
\text { bulkier } \mathrm{Si}-\mathrm{O}-\left[\mathrm{MAOCl}_{2}\right]^{-} \text {In-situ } \\
\text { heterogeneous polymerization }\end{array}$} \\
\hline & $\begin{array}{l}\text { E-1-hexene } \\
\text { copolymer }\end{array}$ & $\begin{array}{l}\text { E-4M1P } \\
\text { copolymer }\end{array}$ & $\begin{array}{l}\text { E-1-hexene } \\
\text { copolymer }\end{array}$ & $\begin{array}{l}\text { E-4M1P } \\
\text { copolymer }\end{array}$ \\
\hline [EEE] & 0.853 & 0.917 & 0.826 & 0.896 \\
\hline [EEC] & 0.046 & 0.043 & 0.058 & 0.071 \\
\hline [CEC] & 0.000 & 0.000 & 0.000 & 0.000 \\
\hline [ECE] & 0.025 & 0.039 & 0.032 & 0.031 \\
\hline [ECC] & 0.076 & 0.000 & 0.085 & 0.000 \\
\hline$[\mathrm{CCC}]$ & 0.000 & 0.001 & 0.000 & 0.002 \\
\hline Average ethylene (major component) mole fraction [E] & 0.899 & 0.960 & 0.884 & 0.967 \\
\hline Average comonomer (minor component) mole fraction [C] & 0.101 & 0.040 & 0.116 & 0.033 \\
\hline Ethylene reactivity ratio $r_{E}$ & 21.78 & 37.26 & 20.6 & 35.62 \\
\hline Comonomer reactivity ratio $r_{C}$ & 0.39 & 0.02 & 0.32 & 0.05 \\
\hline Average reactivity ratio product $<r_{E} r_{C}>\S$ & 8.41 & 0.59 & 6.64 & 1.64 \\
\hline Terminal model $1^{\text {st }}$ order Markov reactivity ratio product $r_{E} r_{C} \S$ & 8.03 & 0.58 & 6.29 & 1.65 \\
\hline Copolymer type (based on $<r_{E} r_{C}>$ values) & Potentially block & Slightly alternating to random & Potentially block & Less blocky \\
\hline$r_{E} / r_{C}$ & 55.85 & $1,863.00$ & 63.38 & 712.40 \\
\hline Average ethylene sequence length $n_{E N M R}$ & 14 & 25 & 12 & 31 \\
\hline$n_{E \text { MPNMR Flory }}$ (number of ethylene units) & 13 & 38 & 10 & 24 \\
\hline$n_{E \text { MPDSC GT }}$ (number of ethylene units) & 36 & 42 & 36 & 46 \\
\hline$n_{E \text { wav DSC GT }}$ (number of ethylene units) & 31 & 37 & 32 & 39 \\
\hline$n_{E \text { wav SSA DSC (number of ethylene units) }}$ & 31 & 38 & 31 & 42 \\
\hline
\end{tabular}

$\mathrm{E}=$ Ethylene; $\mathrm{C}=1$-hexene or 4M1P (as appropriate). $n_{E M P N M R \text { Flory }}$ and $n_{E M P D S C T}$ were determined from Figs. 7 and 12 , respectively. $r_{E}=k_{E E} / k_{E C}$, and $r_{C}=k_{C C} / k_{C E}$, where $k_{E E}$ and $k_{C C}$ are ethylene and comonomer terminal model homo-propagation rate constants. $k_{E C}$ and $k_{C E}$ are the cross-propagation rate constants. $n_{E N M R}=2.1885 \times n_{E \text { wav DSC GT }}-55.634 ; R^{2}=0.9994$.

$\S$ Estimated by applying the relationships listed in References [37, 38]. $<r_{E} r_{C}>\approx r_{E} r_{C}$ confirms terminal model statistical copolymerization mechanism.

The E-1-H average copolymer compositions and microstructural parameters were calculated following the well-known publications of Hsieh and Randall [36], and Seger and Maciel [37]. According to these references, first the mole fractions of the copolymer triad sequences were calculated by using the reported peak assignment procedures (involving the associated collective peak assignment regions) and the Seger-Maciel algorithm. The concentration of a given triad being proportional to the algebraic expression of the concerned peak areas, this algorithm does not require signal calibration. Seger and Maciel have highlighted the advantages of this approach. Next, the monad and diad mole fractions, and the copolymer microstructural parameters of our interest were calculated using the relations reported in References $[37,38]$. The E-4M1P average copolymer compositions and the corresponding microstructural parameters were calculated following the procedure published by Kimura et al. [39]. Table 2 lists the triad and monad mole fractions, average copolymer compositions, and the copolymer microstructural parameters.

The thermodynamically predicted theoretical distribution of ethylene sequence length (between the pendant side chains), that is, the equilibrium crystal length was calculated using the Flory equation $[40,41]$. According to this, the normalized weight fraction $W_{n}$ of the sequence of $n$ ethylene units is related to the ethylene perpetuation probability $p$ through the following expression:

$W_{n}=n(1-p)^{2} p^{n-1}$

For a statistical copolymer with very long chains, $p$ is related to experimental reactivity ratio product $\left\langle r_{E} r_{C}\right\rangle$ and ethylene mole fraction $X_{E}$ as follows [41]:

$p=1-\frac{1-\left[1-4\left(1-\left\langle r_{E} r_{C}\right\rangle\right) X_{E}\left(1-X_{E}\right)\right]^{1 / 2}}{2\left(1-\left\langle r_{E} r_{C}\right\rangle\right) X_{E}} \quad\left\langle r_{E} r_{C}\right\rangle \neq 1$

$p=X_{M}=X_{E} \quad\left\langle r_{E} r_{C}\right\rangle=1$

where $X_{M}$ is the mole fraction of the monomer.

\section{Results and discussion}

\subsection{Reactor operability and as-synthesized polyethylene morphology}

In this section, we discuss the influence of polymerization mode on polyethylene morphology. No reactor fouling and thermal runaway were observed during pseudo-homogeneous and in-situ heterogeneous polymerizations. Fig. 3 shows the SEM-determined morphology of the resulting polyethylenes. The pseudo-homogeneous reference polymerization produced a sort of powdery material, practically consisting of clumped miniature particles, because the reaction primarily occurred in the microemulsion bulk polymerization phase, mainly comprising $n$-hexane. On the other hand, the in-situ heterogeneous polymerization synthesized free-flowing fairly spherical particles, which may be elucidated as follows. Here, apparently a polymer film formed instantaneously around the catalyst particles (due to polymerization) by the active centers created by the contact of ( $\left.{ }^{\mathrm{n}} \mathrm{BuCp}\right)_{2} \mathrm{ZrCl}_{2}$ (an aspecific $\mathrm{C}_{2 v}$-symmetric metallocene) with the MAO-impregnated silica. This film coated the catalyst constituents with a surrounding shell and prevented leaching. Accordingly, the polymer grew on the fragmenting MAO-impregnated silica particles, not in the polymerization diluent, which generated the spherical morphology. This explanation follows the work of Smit et al. [42,43].

\subsection{Polymerization activity versus steric hindrance and boundary layer mass transfer effect}

Here, we revisit comonomer effect (irreversible increase of catalyst activity) from the perspective of (i) steric hindrance due to comonomer molecular branching and MAO anion bulkiness, and (ii) hydrodynamic boundary layer mass transfer effect, illustrated by Fig. 2.

Fig. 4 illustrates how the polymerization modes and the MAO anion- and comonomer types affect the resulting polymerization activity. The pseudo-homogeneous polymerization showed higher homopolymerization catalyst productivity than the in-situ 

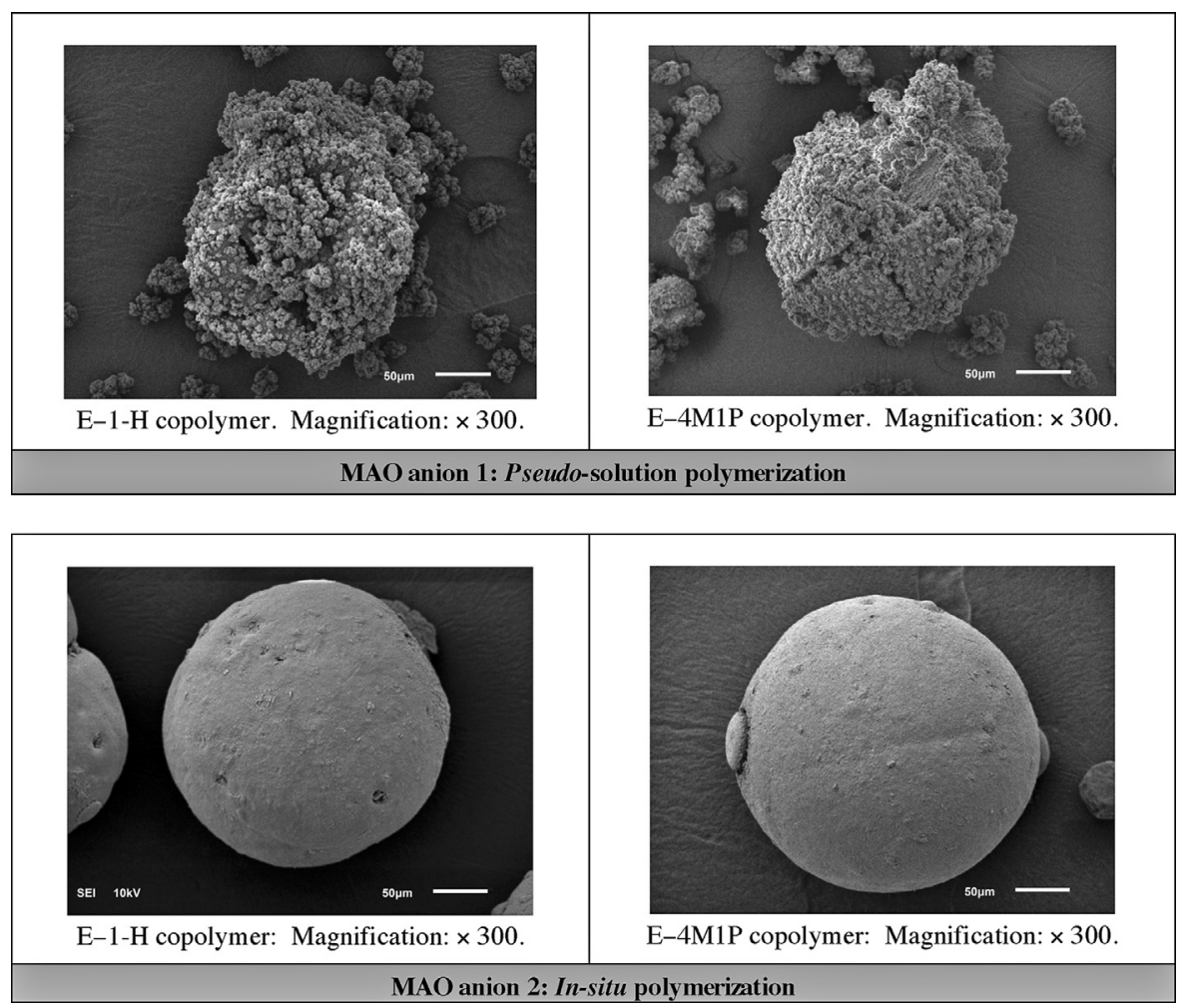

Fig. 3. SEM-determined morphology of the as-synthesized copolymers. To avoid repetition, homopolymer morphology has been excluded.

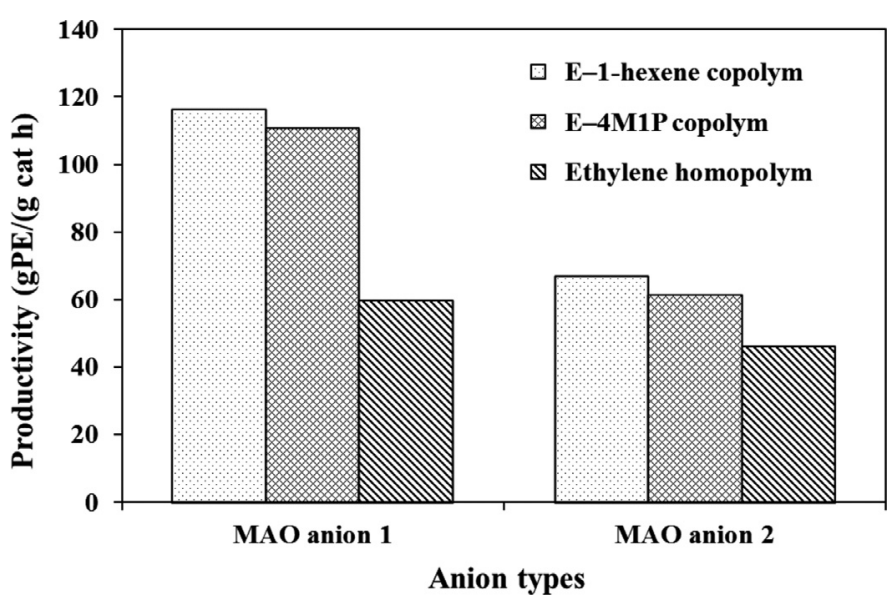

Fig. 4. Influence of cocatalyst anion types and isomeric copolymerization on catalyst productivity and comonomer effect. MAO anion $1 \Rightarrow$ Pseudo-homogeneous polymerization; MAO anion $2 \Rightarrow I n$-situ heterogeneous polymerization.

heterogeneous polymerization. The occurrence of polymerization in the bulk microemulsion phase, devoid of hydrodynamic mass transfer effect, in pseudo-homogeneous polymerization supports this finding. Also, for each MAO anion, the copolymerization catalyst productivity was greater than the corresponding homopolymerization catalyst productivity. Hence, both 1-hexene and 4M1P $\alpha$-olefin comonomers separately introduced positive comonomer effect. However, MAO anion 1 (pseudo-homogeneous polymerization) and 1hexene showed larger comonomer effect than MAO anion 2 (in-situ heterogeneous polymerization) and 4M1P. We shall discuss the influence of this comonomer effect on copolymer intra-chain compositional heterogeneity in Section 3.5. The above findings can be attributed to the following: i. The steric hindrance to comonomer insertion by the branched 4M1P and the bulkier supported MAO anion 2 $\left(\mathrm{Si}-\mathrm{O}-\left[\mathrm{MAOCl}_{2}\right]^{-}\right)$; and

ii. The diffusional mass transfer effect introduced by the hydrodynamic boundary layer $\delta$.

The above factors variedly influenced the following chemically intrinsic phenomena: (i) the zirconocenium-MAO anion separation [20,44-48] (in ethylene homopolymerization) and (ii) the activation of the dormant/sleeping $\mathrm{Zr}^{+}-\mathrm{H}$ catalytic sites [20,49-57] by 1hexene and 4M1P (in ethylene copolymerization). Hence, we observe varying homopolymerization catalyst productivities and comonomer effects, respectively. Note that the closer is the ion-pair separation, the higher is the energy barrier associated with each polymerization step; hence, the less is the catalyst productivity [20,44-48].

\subsection{Polymer molecular weight and chain transfer effect}

We evaluate in this section the comonomer-induced chain transfer effect, measured by molecular weight distribution and its average. The following result is common between MAO anion 1 (pseudohomogeneous polymerization) and anion 2 (in-situ heterogeneous polymerization). Both 1-hexene and 4M1P significantly decreased the weight average molecular weights of the corresponding homopolymers (see Table 1). Also, in each case, the copolymer molecular weight distributions shifted toward the left, generating low molecular weight backbones (see Fig. 5). Hence, 1-hexene and 4M1P, in addition to insertion into the growing copolymer backbone, also acted as in-situ chain transfer agents. In pseudo-homogeneous polymerization, 4M1P acted stronger than 1-hexene as a chain transfer agent while in in-situ heterogeneous polymerization, the order reversed. This phenomenon, being an integral part of the copolymerization mechanism, occurred independent of MAO anion type and the mode of copolymerization (without and with hydrodynamic boundary layer-mediated mass transfer effect). However, these factors 

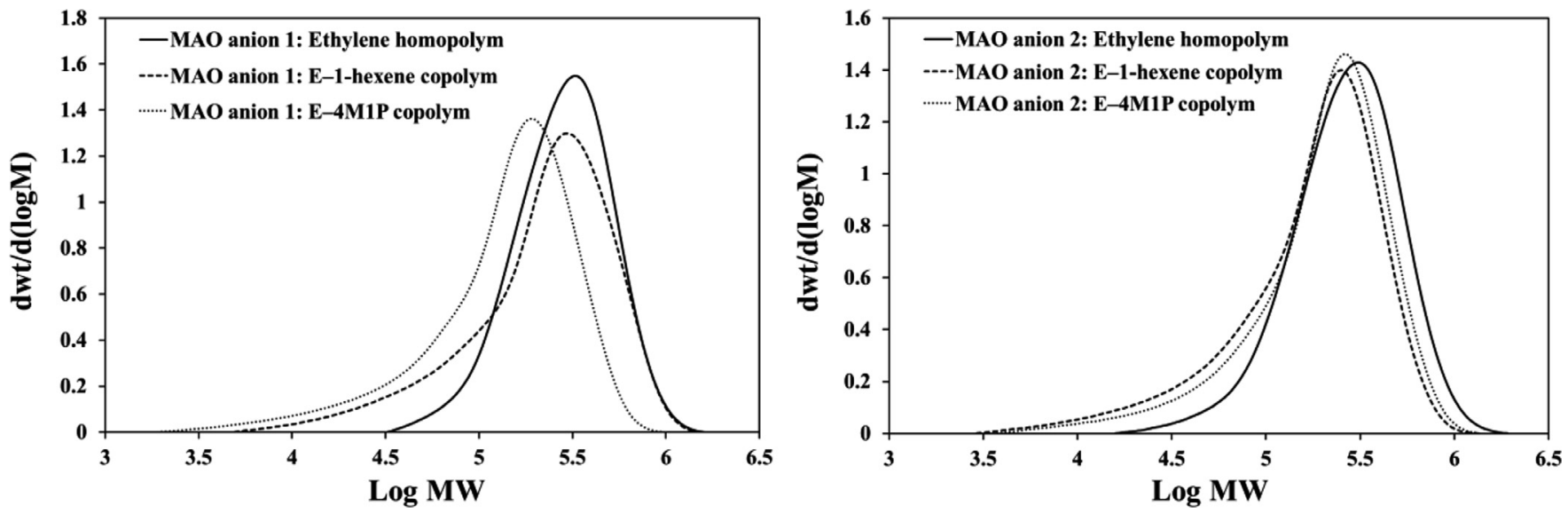

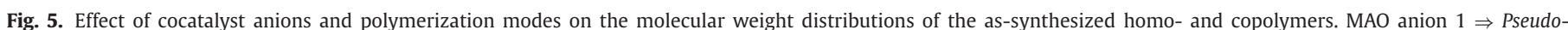
homogeneous polymerization; MAO anion $2 \Rightarrow I n$-situ heterogeneous polymerization.

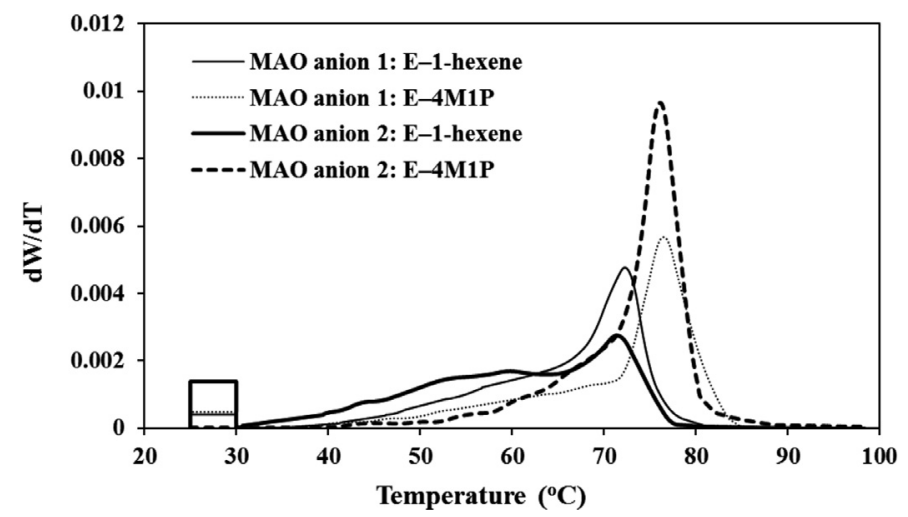

Fig. 6. Comparison of intermolecular composition distributions of the as-synthesized copolymers, measured using Crystaf. MAO anion $1 \Rightarrow$ Pseudo-homogeneous polymerization; MAO anion $2 \Rightarrow I n$-situ heterogeneous polymerization.

particularly affected the level of chain transfer effect. The chain transfer is ascribed to occur as per the following three routes:

- Route A: Termination with ethylene as the last inserted unit, $\beta$ hydrogen transfer to $\mathrm{Zr}^{+}$and/or to ethylene or the comonomer (1-hexene or 4M1P) generates vinyl terminus $\left(\mathrm{CH}_{2}=\mathrm{CHR}\right)$.

- Route B: Termination with ethylene as the last inserted unit, 2, 1 misinsertion of the comonomer, followed by $\beta$-hydrogen elimination to the $\mathrm{Zr}^{+}$active sites generates trans-vinylene terminus $\left(\mathrm{R}_{1} \mathrm{CH}=\mathrm{CHR}_{2} ; \mathrm{R}_{1} \neq \mathrm{R}_{2}\right)$.

- Route C: Termination with ethylene as the last inserted unit, 1, 2 insertion of the comonomer generates vinylidene terminus $\left(\mathrm{CH}_{2}=\mathrm{CR}_{1} \mathrm{R}_{2} ; \mathrm{R}_{1} \neq \mathrm{R}_{2}\right.$ ) (through $\beta$-hydrogen elimination to $\mathrm{Zr}^{+}$ active sites).

The above mechanisms are schematically detailed elsewhere in the literature [25].

\subsection{Copolymer inter-chain composition distribution and copolymerization micromixing/segregation effects}

Here, we evaluate how the lack of molecular level mixing (micromixing), or the occurrence of segregation effect influences isomeric copolymerization inter-chain composition distribution, measured by Crystaf. Note that it is copolymer composition distribution that is particularly sensitive to micromixing/segregation effects [58-60].

Fig. 6 shows that MAO anion 1 (pseudo-homogeneous polymerization) and MAO anion 2 (in-situ heterogeneous polymerization), in the presence of $\left({ }^{\mathrm{n}} \mathrm{BuCp}\right)_{2} \mathrm{ZrCl}_{2}$, synthesized highly broad composition distribution $\mathrm{E}-1-\mathrm{H}$ and $\mathrm{E}-4 \mathrm{M} 1 \mathrm{P}$ copolymers. Also, see the root mean square crystallization temperature $T_{\sigma}$ crystaf values in Table 1. The MAO anion 1 and anion 2 E-4M1P copolymers, during Crystaf cooling, successively crystallized as predominantly ethylene-rich linear ordered backbones (at around $78{ }^{\circ} \mathrm{C}$ ), with sparse comonomer incorporation, to crystallizable $\mathrm{E}-4 \mathrm{M} 1 \mathrm{P}$ backbones having negligible amounts of amorphous/rubbery E-4M1P soluble fractions (0-0.0005). On the other hand, the corresponding E-1-H copolymers did not show ethylene-rich linear ordered backbones. They only demonstrated crystallizable $\mathrm{E}-1$-H backbones with varying amounts of amorphous/rubbery E-1-H soluble fractions (0.0004-0.0014). The absence of ethylene-rich backbones reflects the influence of restricted 4M1P incorporation due to steric hindrance imparted by this $\alpha$-olefin comonomer. The observed common composition distribution broadness demonstrates the presence of strong micromixing/segregation effect [58-60]. This phenomenon can be ascribed to the three-dimensional MAO cage structures that feature the following [61-68]:

i Each MAO structure comprises $n$ different MAO [ $\left.-(\mathrm{AlOMe})_{n}-\right]$ repeat units; and

ii The above MAO structures have preferably one type of defined strong active Lewis acid catalyst site that can be attributed to the $-\mathrm{AlO}_{2} \mathrm{Me}-$ environment [67]. Accordingly, different active site ion-pairs $[\mathrm{Zr}]^{+}[\mathrm{MAO}]_{n}{ }^{-}$are likely to prevail in the experimental zirconocene catalysts. This subject-metallocene active center distribution-has been particularly detailed in some of our recent publications [20,24].

\subsection{Copolymer intra-chain microstructure and copolymerization mechanism}

Here, we discuss the effects of the modes of copolymerization, and cocatalyst anion- and comonomer types on the resulting copolymer intra-chain microstructures and the related copolymerization mechanisms. The copolymer microstructure, in this context, will be described in terms of the following:

i. ${ }^{13} \mathrm{C}$ NMR-determined triad mole fractions and average ethylene sequence/block length $n_{E N M R}$; and

ii. The Flory distribution of ethylene sequence/block length between the pendant $n$-butyl (linear) or $i$-butyl (branched) short side

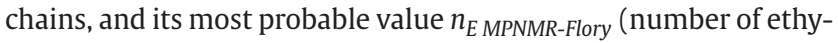
lene units corresponding to the peak of the distribution).

The triad analysis shows that [HEH], [HHH], [CEC], and [ECC], where $\mathrm{C}$ is 4M1P comonomer, in the related copolymers, are zero. The 


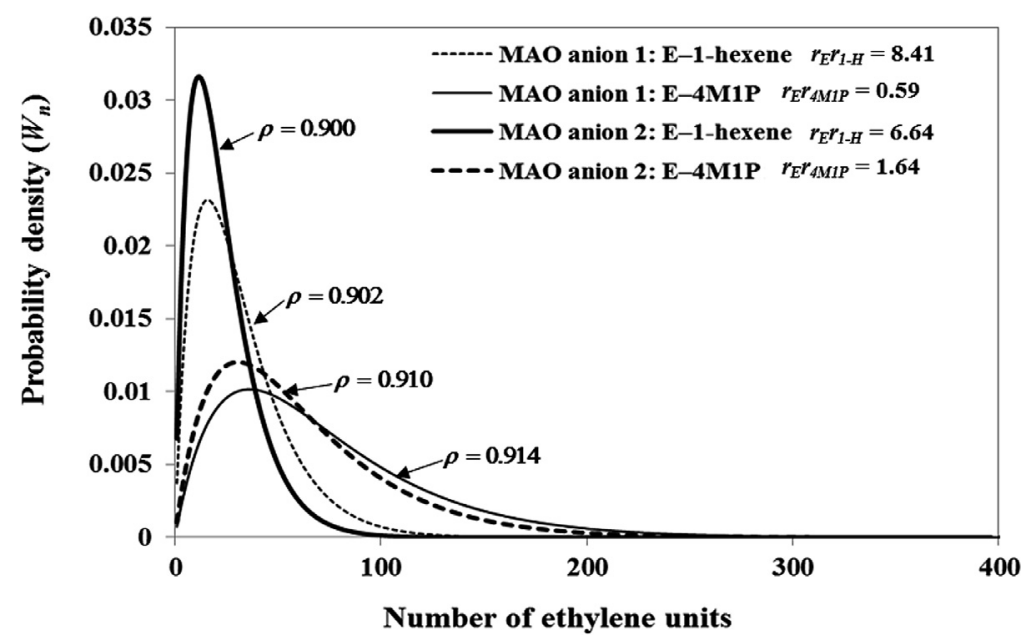

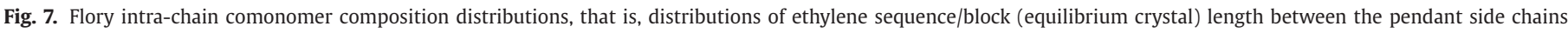
(branches) of the as-synthesized copolymers. MAO anion $1 \Rightarrow$ Pseudo-homogeneous; MAO anion $2 \Rightarrow$ In-situ heterogeneous polymerization.

literature supports this finding [36,69-72]. The remaining triad mole fractions of the as-synthesized copolymers differ among themselves (see Table 2).

Now we discuss the average copolymer compositions in $\mathrm{E}-1-\mathrm{H}$ and $\mathrm{E}-4 \mathrm{M} 1 \mathrm{P}$ copolymers, and correlate them to the corresponding monomer and comonomer reactivity ratios. The E-1-H copolymers showed comparable average ethylene and 1-hexene mole fractions, irrespective of anion types. Similar observation holds for E-4M1P copolymers, as well as ethylene reactivity ratio $r_{E}$ and comonomer reactivity ratio $r_{C}$. These results complement the findings of Fig. 6 Crystaf curves.

${ }^{13} \mathrm{C}$ NMR-determined average reactivity ratio product $\left\langle r_{E} r_{C}>\right.$, in each case, fairly matched the corresponding 1st order Markov reactivity ratio product $r_{E} r_{C}$. Therefore, the terminal model statistical copolymerization mechanism prevailed despite variation in (i) the mode of copolymerization, and (ii) anion- and comonomer types. In other words, the hydrodynamic boundary layer-mediated mass transfer and the variance in the design of the MAO anion (characterized with different electronic and steric effects due to ${ }^{\mathrm{n}} \mathrm{BuCpZrCl}$ ) and coordination environments, did not affect the copolymerization mechanism. However, what about the comonomer insertion process and its spatial positioning along the copolymer backbone? We address this concern as follows.

In the literature $[38,73]$, based on experimental data, ethylene- $\alpha$-olefin copolymers have been classified as follows: (i) random $\left(<r_{E} r_{\alpha \text {-olefin }}>=1\right)$; (ii) slightly alternating to random $\left(<r_{E} r_{\alpha \text {-olefin }}>=0.2-1.0\right)$; (iii) highly alternating $\left(<r_{E} r_{\alpha \text {-olefin }}>=0.005-0.01\right)$; and (iv) blocky character $\left(<r_{E} r_{\alpha \text {-olefin }}>>>1.0\right)$, where $r$ is the reactivity ratio. Accordingly, MAO anion 1 (pseudo-homogeneous polymerization) was prone to produce potentially block E-1-H, and alternating to random E-4M1P copolymers. On the other hand, MAO anion 2 (in-situ heterogeneous polymerization) was apt to synthesize potentially block E-1-H and E-4M1P copolymers. This shows the tendency to generate homosequences of ethylene and $\alpha$-olefin comonomer (1-H or 4M1P) in the polymer backbone (see Table 2). These results demonstrate the combined role played by mass transfer effect (due to hydrodynamic boundary layer $\delta$ ), and MAO anion- and comonomer types on the mode of insertion of the comonomer and its spatial positioning along the copolymer backbone.

For each MAO anion, we note the following:
i. $r_{E}>>r_{C}$;
ii. $r_{1-H}>>r_{4 M 1 P}$; and
iii. $n_{E N M R \mid E-4 M 1 P \text { copolymer }}>n_{E N M R \mid E-1-H \text { copolymer }}$.

Therefore, $R_{E} \gg R_{1-H} \gg R_{4 M 1 P}$, where $R$ is the corresponding homopolymerization rate, argues why 4M1P inserted less than 1hexene in the copolymer backbone. This may be attributed to more steric hindrance imparted by the branched 4M1P comonomer and the increase in $r_{E} / r_{C}$ values. The above finding also aligns with showing less comonomer effect by 4M1P than 1-hexene, irrespective of MAO anion type (see Fig. 4).

Fig. 7 compares the Flory intra-chain comonomer composition distributions of the as-synthesized copolymers. It shows that the intra-chain comonomer composition distribution broadened as the copolymer crystallinity and the density increased. Therefore, the Flory equation is shown to model the eventual partial disruption of the crystal package of the polyethylene chains due to comonomer incorporation. This may be explained as follows. The lower density copolymers incorporated more 1-hexene or 4M1P units in the polymer backbone. As a result, the $n$-butyl or $i$-butyl side chains (short branches) were more crowded along the copolymer backbone. This creates a shorter ethylene sequence/block length between the side branches, making the distribution narrower. See Table $2 n_{E N M R}$ values, which support the above explanation.

\subsection{Thermal behavior of the as-synthesized polyethylenes}

In this section, we discuss the copolymer thermal behaviors in terms of peak melting and crystallization temperatures ( $T_{p m}$ and $T_{p c}$ ), \%crystallinity $\left(X_{c}\right)$, SSA-induced fractionation temperatures (using multiple alternate melting and cooling with intervening annealing), and lamellar thickness distributions (LTDs) and their averages; and compare them with the corresponding homopolymer properties. We observe the following.

In all the copolymers, the incorporation of 1-hexene or 4M1P, with reference to the corresponding homopolymers, depressed the $T_{p m}, T_{p c}$, and $X_{c}$. The depression of these properties, due to 1-hexene, showed to be more than that due to 4M1P (see Table 1).

The above findings are attributed to the comonomer-induced (i) steric hindrance, (ii) structural/enchainment defects, and (iii) the eventual partial disruption of the crystal package of the polyethylene chains, which are reflected in the following properties:

i. Inter-chain copolymer composition distribution (see Fig. 5), and average ethylene composition [E];

ii. Intra-chain copolymer composition distribution, represented by various triad sequences, Flory distribution of ethylene sequence/block (equilibrium crystal) length between the 


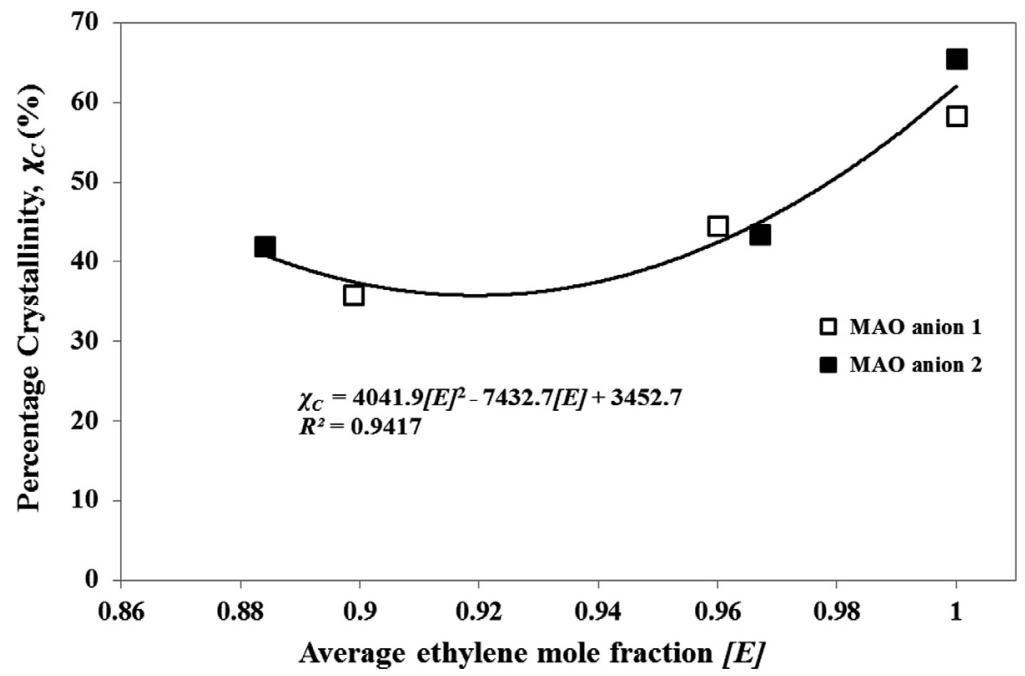

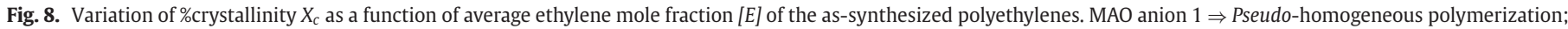
$\mathrm{MAO}$ anion $2 \Rightarrow I n$-situ heterogeneous polymerization.

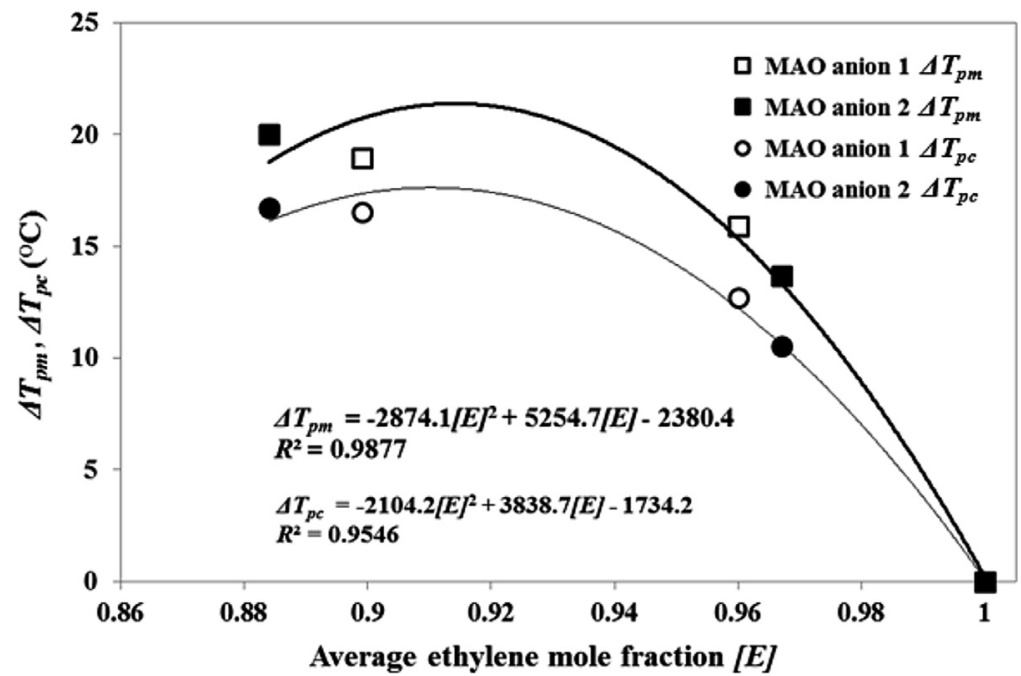

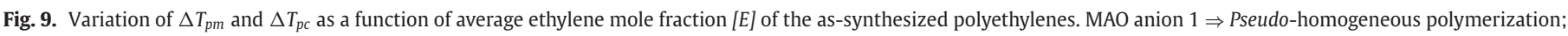
$\mathrm{MAO}$ anion $2 \Rightarrow I n$-situ heterogeneous polymerization.

comonomer side chains; most probable ethylene sequence $n_{E M P N M R}$ Flory ; and average ethylene sequence $n_{E N M R}$; and

iii. Average and most probable lamellar thicknesses ( $L_{\text {wav DSCGT, }}$ $L_{\text {MPDSC GT }}, L_{\text {wav DSC SSA }}$, and $L_{\text {nav DSC SSA }}$ ), which are affected by interas well as intra-chain copolymer composition distributions.

Now we quantitatively evaluate the effects of inter- and/or intrachain copolymer composition distributions on $X_{c}, \Delta T_{p m}$, and $\Delta T_{p c}$ by correlating these thermal properties to $[E], n_{E N M R}, n_{E M P N M R}$ Flory, $L_{\text {wav DSC GT }}, L_{M P D S C}$ GT , and $L_{\text {wav DSC SSA }}$ (as appropriate).

Fig. 8 illustrates how the inter-chain copolymer compositional differences, characterized by average ethylene mole fraction [E], influenced the \%crystallinity $X_{c}$. The following concave-up 2 nd order polynomial, $X_{c}(\%)=4041.0[E]^{2}-7432.7[E]+3452.7$, related $X_{c}$ to $[E]$. On the other hand, concave-down 2nd order polynomials connected $\Delta T_{p m}$ and $\Delta T_{p c}$ to [E] (see Fig. 9). These relations sustain irrespective of variation in comonomer and MAO anion types, and the modes of ethylene polymerization (pseudo-homogeneous versus in-situ heterogeneous). $X_{c}$ increased whereas $\Delta T_{p m}$ and $\Delta T_{p c}$ decreased with the increase in $[E]$; hence, the variational relationship turned out to be inverse and opposite.

Fig. 10, unlike Fig. 9, demonstrates how the \%crystallinity $X_{c}$ varied as a function of average ethylene sequence length $n_{E N M R} . X_{C}$ increased linearly with increasing $n_{E N M R}$, following the relation, $X_{C}=0.4479$ $\times n_{E N M R}+25.514 ; R^{2}=0.9246$. The variation in comonomer and MAO anion types, and the modes of ethylene polymerization (pseudosolution versus in-situ) did not affect this linear relation. This result indicates that the incorporation of 1-hexene or 4M1P shortened $n_{E N M R}$; consequently, the chains, on an average, were more frequently interrupted from folding than the corresponding homopolymers. Accordingly, the intrinsic crystallizability of the resulting copolymer backbones dropped, and $X_{c}$ decreased. $\Delta T_{p m}$ and $\Delta T_{p c}$ also showed to be linearly related to $n_{E N M R}$ but with a decreasing variational trend; $\Delta T_{p m}=-0.3771 n_{E N M R}+30.583, R^{2}=0.9927 ;$ and $\Delta T_{p c}=$ $-0.5733 n_{E N M R}+34.441, R^{2}=0.9971$. Hence, the effect is opposite (see Fig. 11). In summary, we showed (through modeling) that the influence of inter- and intra-chain copolymer composition distributions on depressible polyethylene thermal properties $-X_{c}, \Delta T_{p m}$, and $\Delta T_{p c}$-are qualitatively similar but not the same. To the best of our knowledge, such a finding has not been so far published in the literature.

Fig. 12 mutually compares the Gibbs-Thompson (GT) lamellar thickness distributions of the as-synthesized polyethylenes. We calculated them applying Gibbs-Thompson (GT) equation, the related literature expressions $[24,41,74-77]$, and the DSC data. We valued the most probable lamellar thickness $L_{M P D S C}$ from the peak of each 


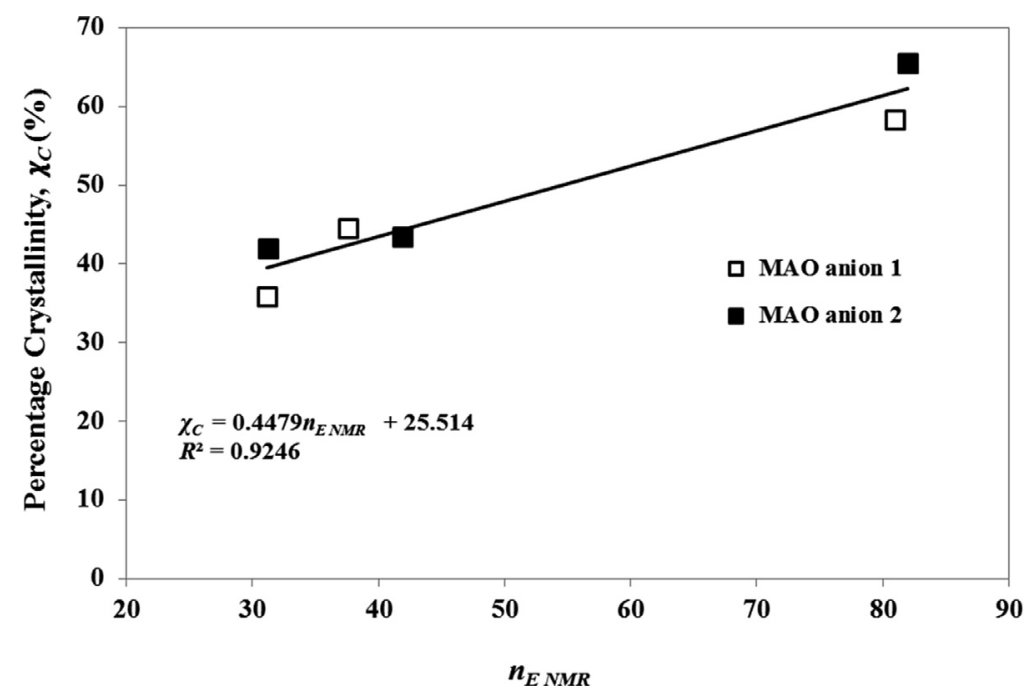

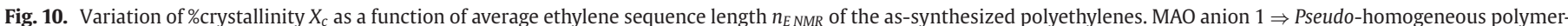
ization; MAO anion $2 \Rightarrow I n$-situ heterogeneous polymerization.

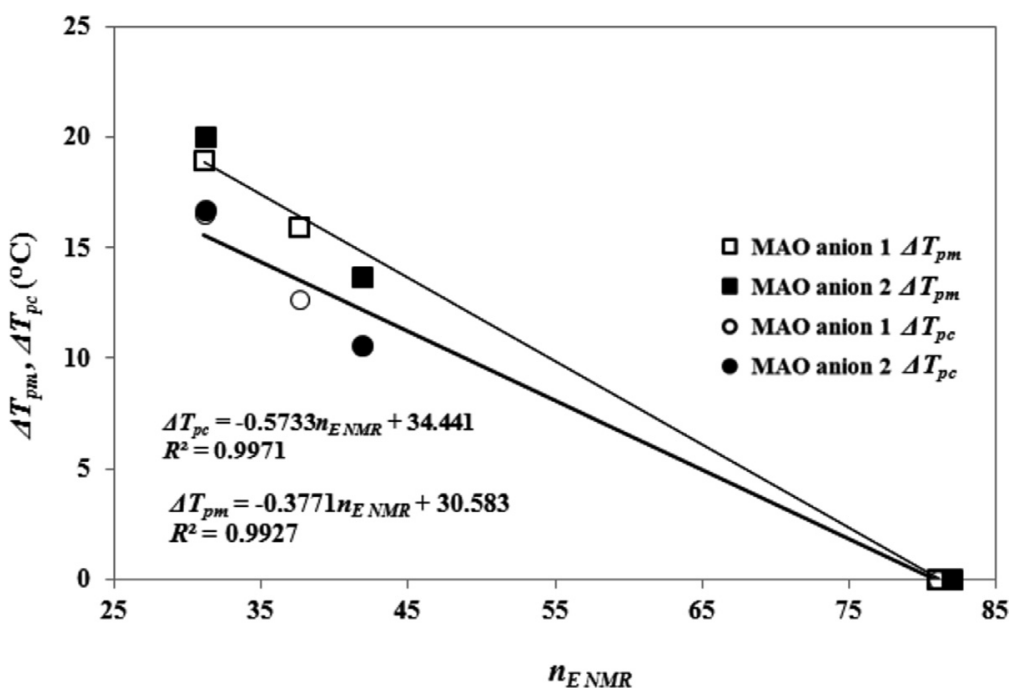

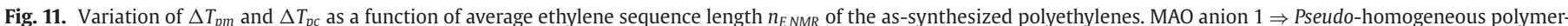
ization; MAO anion $2 \Rightarrow I n$-situ heterogeneous polymerization.
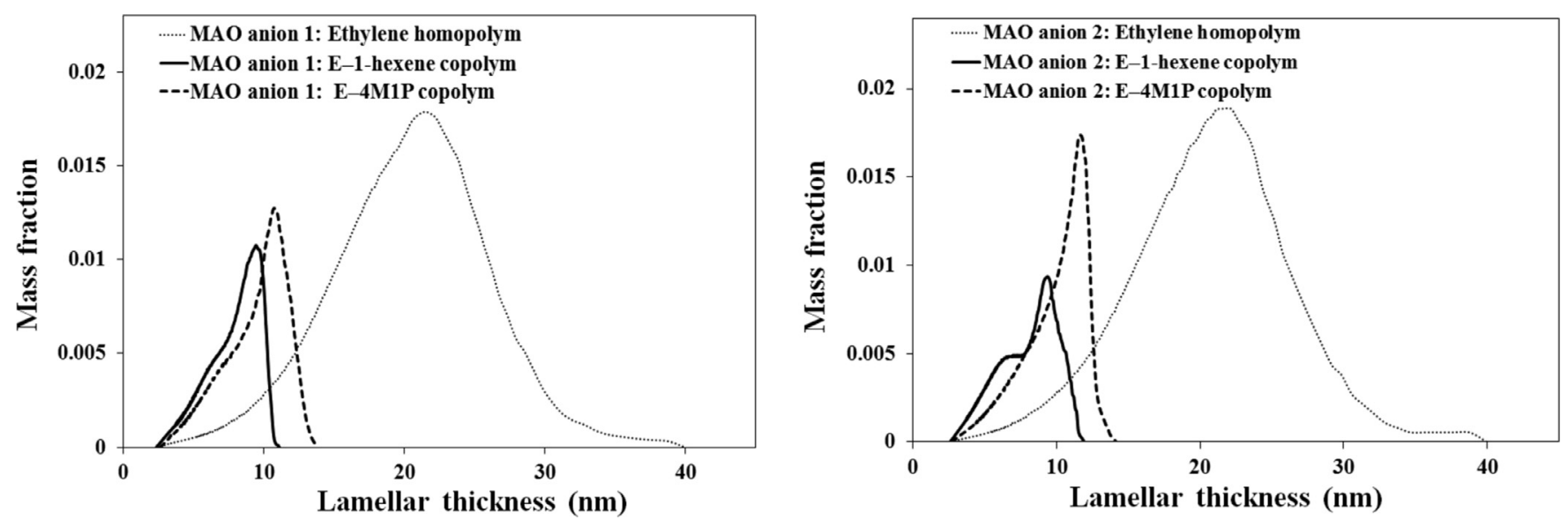

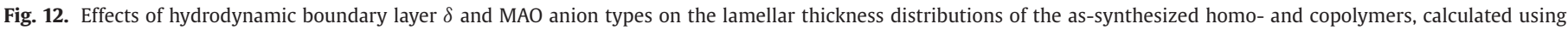
Gibbs-Thompson equation and conventional DSC. MAO $1 \Rightarrow$ Pseudo-homogeneous; MAO $2 \Rightarrow$ In-situ heterogeneous polymerization. 


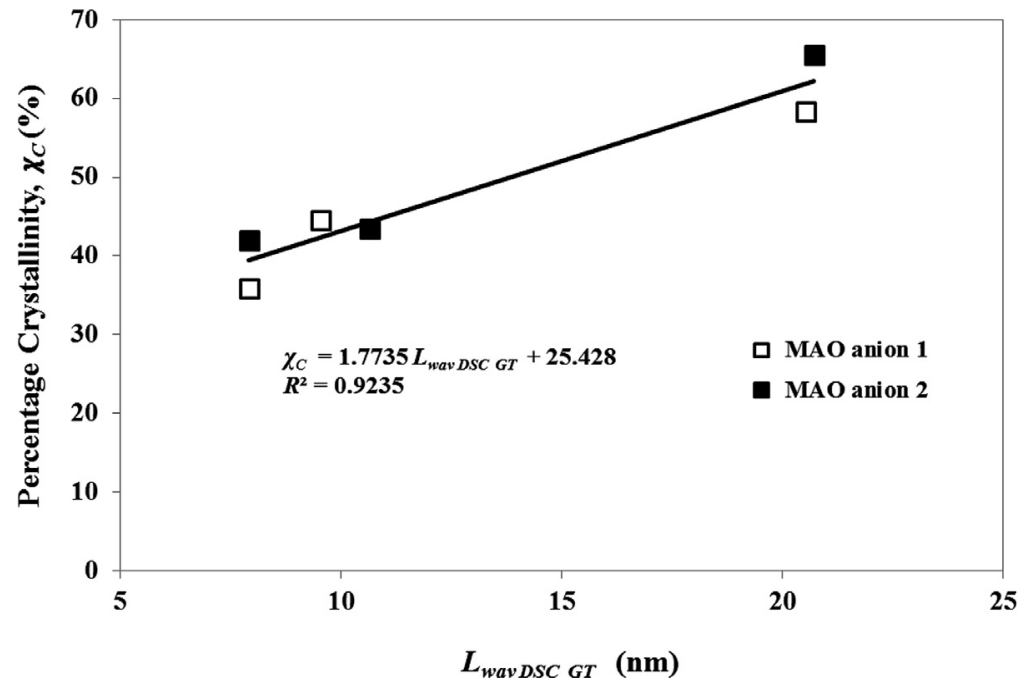

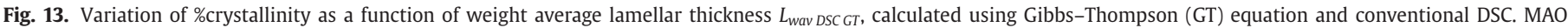
anion $1 \Rightarrow$ Pseudo-homogeneous; MAO anion $2 \Rightarrow$ In-situ heterogeneous polymerization.

lamellar thickness distribution. In these calculations, the following best parametric values were used [74]: $T_{m}^{0}$ (equilibrium melting temperature of a perfect crystal) $=145.5^{\circ} \mathrm{C}, \Delta H_{f}^{0}$ (heat of fusion per unit volume for the perfect crystal $)=290 \mathrm{Jcm}^{-3}$, and $\sigma_{\text {ssfe }}($ crystallite specific surface free energy) $=90 \mathrm{mJm}^{-2}$. However, $T_{m, \text { copolym }}^{0}$ (equilibrium melting temperature of the copolymer) was found as reported in the literature [41,74-77]. $L_{\text {MPDSC GT }}$ was next converted into the most probable ethylene sequence $n_{E M P D S C} G T$ by dividing it with the length of an ethylene repeat unit $(0.254 \mathrm{~nm})$. The weight average lamellar thickness $L_{\text {wav DSC GT }}$ was estimated using the whole LTD. We summarize below the findings of Fig. 12 and Table 1.

With respect to MAO anion 1 (pseudo-homogeneous polymerization), $L_{\text {wav DSC GT }}, L_{\text {MPDSC GT }}, L_{\text {wav DSC SSA }}$, and $\sigma_{\text {lamellar thickness }}$ decreased in the following order: homopolymer $>$ E-4M1P copolymer $>$ E-1hexene copolymer. The corresponding lamellar thickness distributions also translated toward left in the same order. The same variational trends persisted with MAO anion 2 (in-situ heterogeneous polymerization). Note that the ethylene homopolymer has neither inter- nor intra-chain composition distributions. On the other hand, the copolymers have such distributions which influenced the corresponding $L_{\text {wav DSC GT }}, L_{M P D S C}$ GT,$L_{\text {wav DSC SSA }}$, and $\sigma_{\text {lamellar thickness }}$ values. Therefore, the Gibbs-Thompson (GT) equation successfully modeled the influence of comonomer-induced (i) structural/enchainment defects and (ii) the eventual partial disruption of the crystal package of the polyethylene chains on the resulting polymer melting behavior.

Fig. 13 shows that the \%crystallinity $X_{c}$ of the as-synthesized polyethylenes increased linearly as a function of $L_{\text {wav DSC GT }} ; X_{C}(\%)$ $=1.7735 \times L_{\text {wav DSC GT }}+25.428 ; R^{2}=0.9235$. Despite variation in comonomer and MAO anion types and the modes of polymerization (pseudo-homogeneous versus in-situ heterogeneous), this linear relation prevailed. This finding has important physical significance. This indicates that the homopolymers and the copolymers undergo similar chain folding behavior. Repulsive energy generated between ethylene sequences and the butyl branch (that exerts steric hindrance) increased. The incorporation of 4M1P and 1-hexene created the iso- and $n$-butyl branches, respectively. Consequently, they refrained from chain folding, and made the interlamellar amorphous phase. This means that the structural/enchainment defects due to 4M1P or 1-hexene were excluded from the pure polyethylene-phase crystal lattice. The [ECC] and [CCC] values (where $\mathrm{C}=\mathrm{H}$ or $4 \mathrm{M} 1 \mathrm{P}$ ) of Table 2 as well as the relevant literature support this conclusion [41,78-82]. The 4M1P or 1-hexene homosequence was not long enough to arrange in a crystal lattice. Note that the formation of such amorphous and crystalline phases influences the copolymer mechanical and various end-use properties. In parallel, Fig. 13 summarizes how Gibbs-Thompson (GT) equation successfully modeled the combined influence of comonomer-induced inter- and intra-chain copolymer composition distributions on the resulting polyethylene bulk crystallinity. The above linear increasing crystallinity relation also holds for $L_{\text {MPDSC GT }}$ because $L_{\text {wav DSC GT }}$ and $L_{\text {MPDSC GT }}$ are linearly related; $L_{\text {wav DSC GT }}=0.9584 \times L_{M P D S C} G T+1.663 ; R^{2}=0.9976$.

Now, we discuss the multiple alternate melting and cooling behavior (with intervening annealing) of the as-synthesized copolymers. They displayed similar successive self-nucleation and annealing (SSA) thermal fractionation melting peaks. For example, E-1hexene and E-4M1P copolymers, synthesized by $\left({ }^{\mathrm{n}} \mathrm{BuCp}\right)_{2} \mathrm{ZrCl}_{2}$ and MAO anion 1 (pseudo-homogeneous polymerization), showed the following five temperature peaks: $100,106,111,115$, and $118{ }^{\circ} \mathrm{C}$. The difference in comonomer type, that is, E-4M1P did not affect this endothermic temperature series. We even notice the same comonomer-independent temperature series, augmented by $124^{\circ} \mathrm{C}$, for the above copolymers prepared by $\left({ }^{\mathrm{n}} \mathrm{BuCp}\right)_{2} \mathrm{ZrCl}_{2}$ and MAO anion 2 (in-situ heterogeneous polymerization) (see Figs. 14 and 15). We calculated $n_{E \text { wav DSC SSA }}$ using these temperatures, Gibbs-Thompson (GT) equation, and the length of an ethylene repeat unit $(0.254 \mathrm{~nm})$. $n_{E \text { wav DSC SSA }}$ was found to correlate to $n_{E N M R}$ as follows: $n_{E \text { wav DSC SSA }}$ $=0.3554 \times n_{E N M R}+28.040 ; R^{2}=0.9924$. We already established that $X_{C}=0.4479 \times n_{E N M R}+25.514 ; R^{2}=0.9246$. Hence, these copolymers have varying crystallizable lengths of PE sequences; however, their mass fractions differed (Fig. 15). Based on this finding and the exclusion of the butyl group from chain folding (Fig. 13), we can remark that the SSA trace of each copolymer also indicates the structural defects resulting from comonomer-introduced butyl branches. This was masked in Crystaf analysis (Fig. 6). However, SSA DSC showed it with much better resolution than Crystaf. The above correlations, to the best of our knowledge, are new and insightful.

Each SSA peak signifies a population of backbones that have the same side chain branch (SCB) content, crystallinity, and lamellar thickness. SCB is inversely connected to the latter two, which are directly related by $X_{c}(\%)=1.7735 \times L_{\text {wav DSC GT }}+25.428 ; R^{2}=0.9235$. Therefore, the branch content decreased, and the lamellar thickness increased with the increase in these peak melting temperatures. Note that in SSA fractionation, the polymer undergoes multiple alternate melting and crystallization processes (without physical separation of 


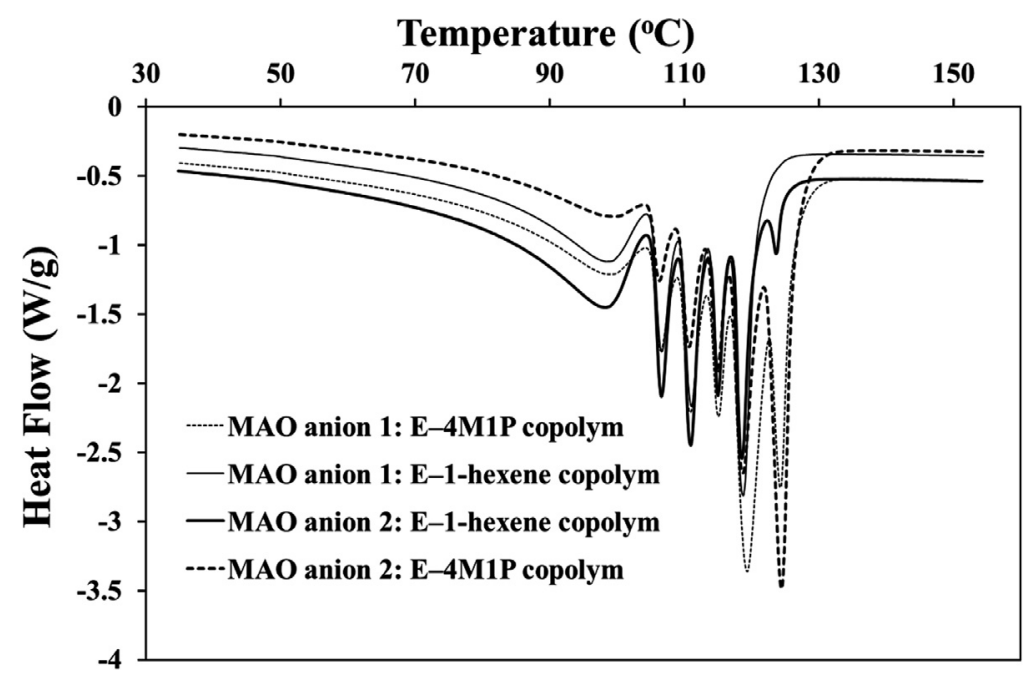

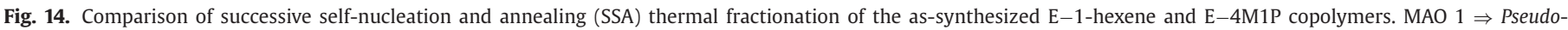
homogeneous; MAO $2 \Rightarrow$ In-situ heterogeneous polymerization.
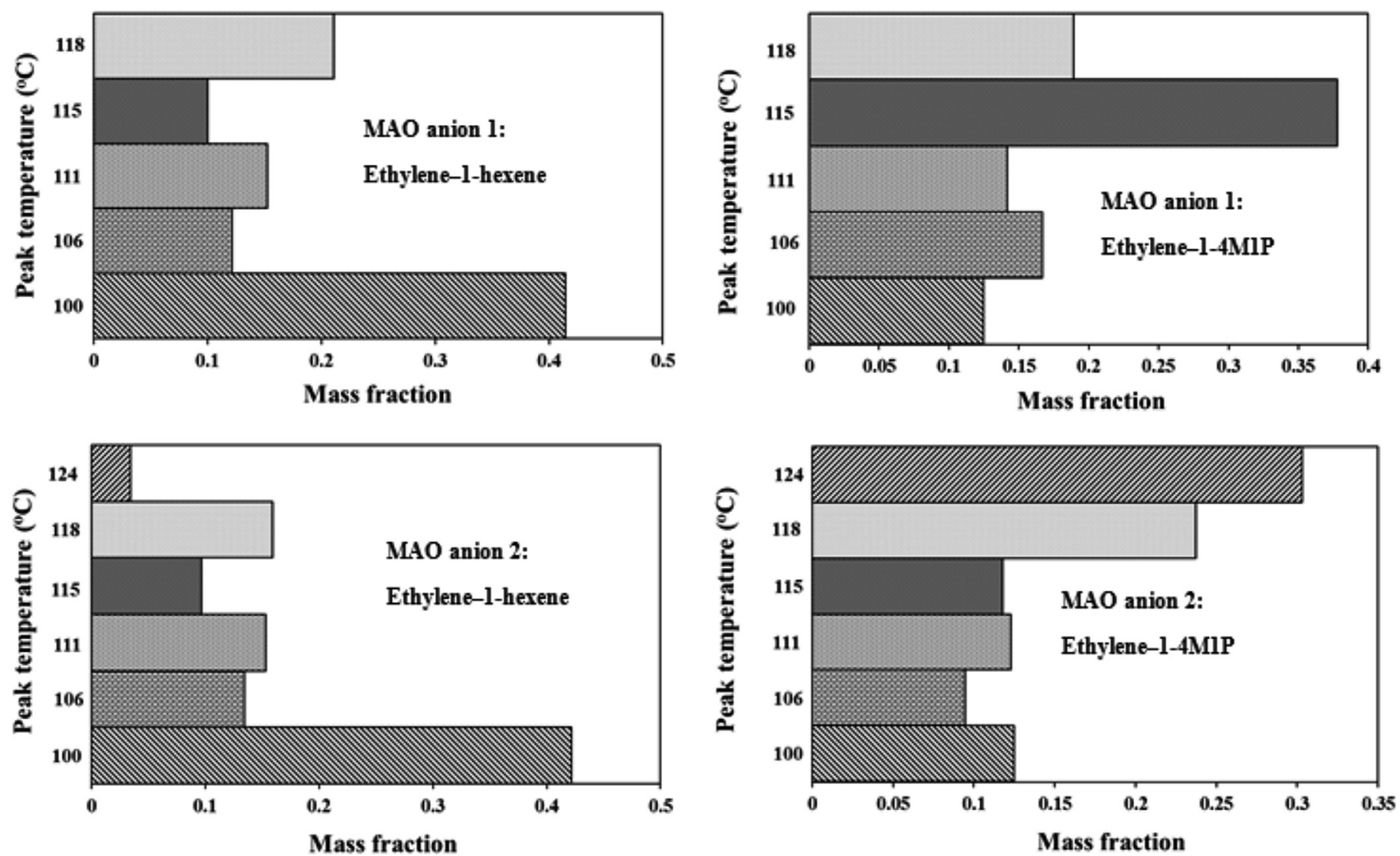

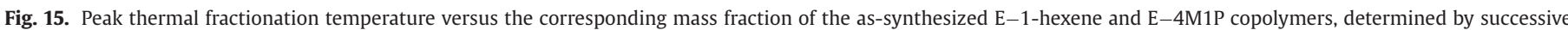
self-nucleation and annealing (SSA) technique. MAO $1 \Rightarrow$ Pseudo-homogeneous; MAO $2 \Rightarrow$ In-situ heterogeneous polymerization.

the chains) as the temperature decreases. Therefore, it is sensitive to linear and uninterrupted chain sequences; hence to both intra- and inter-chain defects [26-31]. The ${ }^{13} \mathrm{C}$ NMR results, reported earlier, complement this remark.

Fig. 15 shows that the discrete SSA DSC peak temperature distributions of the as-synthesized copolymers differed among themselves. This originates from the catalyst active site, that is, ion-pair distribution (due to the coexistence of multiple MAO structures), and the variation in the design of MAO anion.

\section{Conclusions}

Metallocenes, being capable of undergoing remarkable structural variations, have several competitive advantages over the conventional Ziegler-Natta (Z-N) catalysts. Despite so, metallocene industrial polyolefin processes are far less than the most-prevalent $\mathrm{Z}-\mathrm{N}$ ones. Therefore, it is important to investigate metallocene catalysis from an applied and engineering research viewpoint. The present study is a modest contribution toward this direction. It reports a 
novel general conceptual framework that can be easily experimented to evaluate the effects of the following three factors-hydrodynamic boundary layer (HBL), MAO anion design, and comonomer steric hindrance-on metallocene-catalyzed ethylene polymerization. We illustrated this conceptual framework by conducting homo- and isomeric copolymerization of ethylene with 1-hexene and 4-methyl1-pentene in the presence of $\left({ }^{\mathrm{n}} \mathrm{BuCp}\right)_{2} \mathrm{ZrCl}_{2}$, using (i) MAO anion 1 (unsupported $\left[\mathrm{MAOCl}_{2}\right]^{-}$) and pseudo-homogeneous reference polymerization (developed in our laboratory), and (ii) the bulky MAO anion 2 (supported $\mathrm{Si}-\mathrm{O}-\left[\mathrm{MAOCl}_{2}\right]^{-}$) and in-situ heterogeneous polymerization.

The above factors variedly affected the polymer morphology, catalyst productivity, molecular weight distribution, inter- and intrachain composition distributions, and selected thermal properties, excluding the copolymerization and crystallization mechanisms. The polymer morphology, catalyst productivity, molecular weight distribution, and inter-chain composition distribution were eventually correlated to the locus of polymerization, comonomer effect, in-situ chain transfer process, and micromixing effect, respectively. The inter-chain composition distribution (copolymer microstructure) was characterized in terms of various triad sequences, Flory ethylene sequence distribution, most probable ethylene sequence $n_{E M P N M R}$ Flory ; and average ethylene sequence $n_{E N M R}$. The thermal properties were measured in terms of peak melting and crystallization temperatures $\left(T_{p m}\right.$ and $T_{p c}$ ), \%crystallinity $\left(X_{c}\right)$, melt fractionation temperatures (determined using successive self-nucleation and annealing (SSA) technique), and lamellar thickness distributions (LTDs) and their averages. They were mathematically correlated to the afore-said representative parameters of microstructural composition distributions. The resulting correlations showed to be perceptive. The comonomer-induced structural/enchainment defects and the eventual partial disruption of the crystal package of the polyethylene chains were successfully modeled using Flory and Gibbs-Thompson equations. The present approach to the problem generated several new and insightful findings, and it can also be applied to study ethylene- $\alpha$-olefin copolymerization, performed using MAO-activated non-metallocene precatalysts.

\section{Acknowledgements}

The authors greatly acknowledge the financial support provided for this study by King Abdulaziz City for Science and Technology (KACST) via the Science \& Technology Unit at King Fahd University of Petroleum \& Minerals (KFUPM) through Project Number 14-PET283-04 as part of the National Science and Technology Innovation Plan (MAARIFAH). The technical assistance provided by the Center for Refining \& Petrochemicals (CRP) and the Center for Engineering Research at the Research Institute, KFUPM, Dhahran, Saudi Arabia; the Department of Chemical Engineering at KFUPM; and NMR Core Laboratory, Thuwal, King Abdullah University of Science \& Technology (KAUST), Saudi Arabia; is also gratefully acknowledged. The technical assistance of Messrs. Anwar Hossaen and Sarath P. Unnikari; and the gift of 1-hexene by United Petrochemicals, an affiliate of Saudi Basic Industries Corporation (SABIC), are thankfully appreciated.

\section{References}

[1] Hlatky GG. Heterogeneous single-site catalysts for olefin polymerization. Chem Rev 2000;100:1347-76.

[2] Severn JR, Chadwick JC, Duchateau R, Friederichs N. Bound but not gaggedimmobilizing single-site $\alpha$-olefin polymerization catalysts. Chem Rev 2005; $105: 4073-147$

[3] Chum PS, Swogger KW. Olefin polymer technologies-History and recent progress at the Dow Chemical Company. Prog Polym Sci 2008:33:797-819.

[4] Choi Y, Soares JBP. Supported single-site catalysts for slurry and gas-phase olefin polymerization. Can J Chem Eng 2012;90:646-71.

[5] Vaughan A, Davis DS, Hagadorn JR. Industrial catalysts for alkene polymerization. Polym Sci: A Compr Ref 2012;3:657-672.

[6] Atiqullah M, Akhtar MN, Faiz M, Moman A, Abu-Raqabah AH, Khan JH, Wazeer MI Surface chemistry of selected supported metallocene catalysts studied by DRFTIR, CPMAS NMR, and XPS techniques. Sur Interf Anal 2006;38:1319-1327.
[7] Alt HG. Intelligent catalysts for ethylene oligomerization and polymerization. Polyolefins J 2015;2:17-25.

[8] Kaminsky W, Fernandes M. Discovery and development of metallocene-based polyolefins with special properties. Polyolefins J 2015;2:1-16

[9] Ivanchev SS, Badaev VK, Ivancheva NI, Budtov VP, Ya KS, Lemenovskii D. Homopolymerization of 4-methyl-1-pentene and its copolymerization with ethylene in the presence of zirconocene catalysts. Polym. Sci Series A: Chem Phys 2000;42:126-131.

[10] Xu G, Cheng D. Homo- and copolymerization of 4-methyl-1-pentene and ethylene with group 4 ansa-cyclopentadienylamido complexes. Macromolecules 2001;34:2040-2047.

[11] Losio S, Boccia AC, Sacchi MC. Ethylene/4-methyl-1-pentene copolymers by a constrained geometry catalyst: advances in ${ }^{13} \mathrm{C}$ NMR assignment. Macromol. Chem Phys 2008;209:1115-28.

[12] Losio S, Stagnaro P, Motta T, Sacchi MC. Penultimate-unit effect in ethene/4-methyl-1-pentene copolymerization for a sequential distribution of comonomers. Macromolecules 2008;41:1104-1111.

[13] Mauler RS, Galland GB, Scipioni RS, Quijada ZR. The effect of the ethylene pressure on its reaction with 1-hexene, 1-octene and 4-methyl-1-pentene. Polym Bull 1996;37:469-474.

[14] Irwin LJ, Reibenspies JH, Miller SAJ. A sterically expanded constrained geometry catalyst for highly active olefin polymerization and copolymerization: an unyielding comonomer effect. Jour Am Chem Soc 2004;126:16716-17.

[15] Galimberti M, Piemontesi F, Alagia L, Losio S, Boragno L, Stagnaro P, Sacchi MC. Toward block copolymers from nonliving isospecific single-site catalytic systems. J Polym Sci Part A: Polym Chem 2010;48:2063-2075.

[16] Awudza JAM, Tait PJT. The comonomer effect in ethylene/ $\alpha$-olefin copolymerization using homogeneous and silica-supported $\mathrm{Cp}_{2} \mathrm{ZrCl}_{2} / \mathrm{MAO}$ catalyst systems: Some insights from the kinetics of polymerization, active center studies, and polymerization temperature. J Polym Sci Part A: Polym Chem 2008;46:267-77.

[17] Chu KJ, Soares JBP, Penlidis A. Variation of molecular weight distribution (MWD) and short chain branching distribution (SCBD) of ethylene/1-hexene copolymers produced with different in-situ supported metallocene catalysts. Macromol Chem Phys 2000;201:340-8.

[18] Chu KJ, Soares JBP, Penlidis A. Effect of hydrogen on ethylene polymerization using in-situ supported metallocene catalysts. Macromol Chem Phys 2000;201:552-7.

[19] Bird RB, Stewart WE, Lightfoot EN. Transport phenomena. Revised 2nd ed. New York: John Wiley; 2008

[20] Atiqullah M, Anantawaraskul S, Emwas AM, Al-Harthi MA, Hussain I, Ul-Hamid A, Hossaen A. Silica-suppoted ( $\left.{ }^{\mathrm{n}} \mathrm{BuCp}\right)_{2} \mathrm{ZrCl}_{2}$ : Effect of catalyst active center distribution on ethylene-1-hexene copolymerization. Polym Intl 2014:63:955-72.

[21] Sami A, David E, Fréchette M. Procedure for evaluating the crystallinity from Xray diffraction scans of high and low density polyethylene $/ \mathrm{SiO}_{2}$ composites. In: Proceedings of Annual Report on the 10th Conference on Electrical Insulation and Dielectric Phenomena (CEIDP), IEEE Dielectrics and Electrical Insulation Society; 2010.

[22] Wood-Adams PM, Dealy JM, DeGroot AW, Redwine OD. Effect of molecular structure on the linear viscoelastic behavior of polyethylene. Macromolecules 2000;33:7489-99.

[23] Wignall GD, Alamo RG, Laondono JD, Mandelkern L, Kim MH, Lin JS, et al. Morphology of blends of linear and short-chain branched polyethylenes in the solid state by small-angle neutron and X-ray scattering, differential scanning calorimetry, and transmission electron microscopy. Macromolecules 2000;33:551-61.

[24] Atiqullah M, Anantawaraskul S, Emwas AM, Al-Harthi MA. Hussain I, Ul-Hamid A, Hossaen A. Effects of heterogeneous ( $\left.{ }^{\mathrm{n}} \mathrm{BuCp}\right)_{2} \mathrm{ZrCl}_{2}$ catalyst active center distribution on ethylene-1-hexene copolymer microstructure and thermal behaviors. Indus Eng Chem Res 2013;52:9359-9373.

[25] Atiqullah M, Al-Harthi MA, Anantawaraskul S, Emwas AM. Ethylene homo- and copolymerization chain-transfers: a perspective from supported $\left({ }^{n} \mathrm{BuCp}\right)_{2} \mathrm{ZrCl}_{2}$ catalyst active centre distribution. J Chem Sci 2015;127:717-28.

[26] Müller AJ, Hernández ZH, Arnal ML, Sánchez J. Successive selfnucleating/annealing (SSA): a novel technique to study molecular segregation during crystallization. J Polym Bull 1997;39:4650-472.

[27] Czaja K, Sacher B, Białek M. Studies of intermolecular heterogeneity distribution in ethylene/1-hexene copolymers using DSC method. J Therm Anal Calorim 2002;67:547-54.

[28] Müller AJ, Arnal ML. Thermal fractionation of polymers. Prog Polym Sci. (Oxford). 2005;30:559-603.

[29] Białek M, Czaja K, Sacher-Majewska B. Studies of structural composition distribution heterogeneity in ethylene/1-hexene copolymers using thermal fractionation technique (SSA): effect of catalyst structure. Thermochim Acta 2005;429:149-54.

[30] Lorenzo AT, Arnal ML, Müller AJ, De Fierro AB, Abetz V. High speed SSA thermal fractionation and limitations to the determination of lamellar sizes and their distributions. Macromol Chem Phys 2006;207:39-49.

[31] De Ga'scue BR, Herna'ndez JLPG, Vallés EM. Use of the successive self-nucleation and annealing technique to characterize 60 Co gamma irradiated HDPEs. J Therm Anal Calorim 2011;103:669-78.

[32] Czaja K, Sacher B, Białek M. Studies of intermolecular heterogeneity distribution in ethylene/1-hexene copolymers using DSC method. J Therm Anal Calorim 2002;67:547-54.

[33] Monrabal B. Crystallization analysis fractionation: a new technique for the analysis of branching distribution in polyolefins. J Appl Polym Sci 1994;52:491-9.

[34] Monrabal B. Crystaf: crystallization analysis fractionation. A new approach to the composition analysis of semicrystalline polymers. Macromol Symp 1996;110:816. 
[35] Sarzotti DM, Soares JBP, Penlidis A. Ethylene/1-hexene copolymers synthesized with a single-site catalyst: crystallization analysais fractionation, modeling, and reactivity ratio estimation. J Polym Sci Part B: Polym Phys 2002;40:2595-611.

[36] Hsieh ET, Randall JC. Monomer sequence distributions in ethylene-1-hexene copolymers. Macromolecules 1982;15:1402-6.

[37] Seger MR, Maciel GE. Quantitative 13C NMR analysis of sequence distributions in poly(ethylene-co-1-hexene). Anal Chem 2004;76:5734-47.

[38] Hung J, Cole AP, Waymouth RM. Control of sequence distribution of ethylene copolymers: influence of comonomer sequence on the melting behavior of ethylene copolymers. Macromolecules 2003;36:2454-63.

[39] Kimura K, Yuasa S, Maru Y. Carbon-13 nuclear magnetic resonance study of ethylene-1-octene and ethylene-4-methyl-1-pentene copolymers. Polymer $1984 ; 25: 441-446$.

[40] Flory PJ. Theory of crystallization in copolymers. Trans Faraday Soc 1955;51:84857.

[41] Hosoda S, Nozue Y, Kawashima Y, Suita K, Seno S, Nagamatsu T. Effect of the sequence length distribution on the lamellar crystal thickness and thickness distribution of polyethylene: perfectly equisequential ADMET polyethylene vs ethylene/ $\alpha$-olefin copolymer. Macromolecules 2011;44:313-19.

[42] Smit M, Zheng X, Loos J, Chadwick JC, Koning CE. Effects of methylaluminoxane immobilization on silica on the performance of zirconocene catalysts in propylene polymerization. J Polym Sci Part A: Polym Chem 2005;43:2734-48.

[43] Smit MX, Zheng R, Brüll J, Loos JC, Chadwick J, Koning CE. Effect of 1-hexene comonomer on polyethylene particle growth and copolymer chemical composition distribution. J Polym Sci Part A: Polym Chem 2006;44:2883-90.

[44] Wang Q, Song L, Zhao YL. UV-Visible spectroscopic study of racEt(Ind) ${ }_{2} \mathrm{ZrCl}_{2}$ /aluminoxanes. Macromol Rapid Commun 2001;22:1030-4.

[45] Macchioni A. Ion Pairing in transition-metal organometallic chemistry. Chem Rev 2005; 105:2039-73.

[45] Bochmann M. The chemistry of catalyst cctivation: the case of Group 4 colymerization catalysts. Organometallics 2010;29:4711-40.

[47] Wannaborworn M, Praserthdam P, Jongsomjit B. Observation of different catalytic activity of various 1 -olefins during ethylene/1-olefin copolymerization with homogeneous metallocene catalysts. Molecules 2011;16:373-83.

[48] Ustynyuk LY, Fushman EA, Lalayan SS, Nifantév IE. Zirconocene catalysts for olefin polymerization: a comparative DFT study of systems with Al- and B-containing activators. Organomet Chem 2012;700:166-79.

[49] Karol FJ, Sun-Chueh KSC, Cann KJ. Comonomer effects with high-activity titanium- and vanadium-based catalysts for ethylene polymerization. J Polym Sci Part A: Polym Chem 1993;31:2541-53.

[50] Pasquet V, Spitz R. Irreversible activation effects in ethylene polymerization. Die Makromol Chem 1993:194:451-61.

[51] Koivumiiki J, Seppala JV. Observations on the rate enhancement effect with magnesium chloride/titanium tetrachloride and dicyclopentadienylzirconium dichloride $\left(\mathrm{Cp}_{2} \mathrm{ZrCl}_{2}\right)$ catalyst systems upon 1-hexene addition. Macromolecules 1993;26:5535-8

[52] Schaverien CJ, Ernst R, Schut P, Dall'Occo T. Ethylene Bis(2-indenyl) Zirconocenes: a new class of diastereomeric metallocenes for the copolymerization of $\alpha$-olefins. Organometallics 2001;20:3436-52.

[53] de Freitas AJD, dos Santos JHD, Meneghetti SMP, Meneghetti MR. Polymerization of ethylene: some aspects of metallocene catalyst stabilization under homogeneous and heterogeneous reaction conditions. J Appl Polym Sci 2011;119:3051-7.

[54] Chang HS, Song WD, Chu KJ, Ihm SK. Effects of removing THF from the titanium trichloride(AA)/Magnesium Chloride/THF catalyst system on the ethylenepropylene copolymerization mechanism. Macromolecules 1992;25:2086-92.

[55] Quijada R, Rojas R, Mauler RS, Galland GB, Scipioni RB. Study of the effect of the monomer pressure on the copolymerization of ethylene with 1-hexene. J Appl Polym Sci 1997:64:2567-74.

[56] Chu KJ, Shan CLP, Soares JBP, Penlidis A. Copolymerization of ethylene and 1-hexene with in-situ supported Et(Ind) ${ }_{2} \mathrm{ZrCl}_{2}$. Macromol Chem Phys 1999;200:2372-6.

[57] Kissin YV, Mink RI, Nowlin TE, Brandolini AJ. Heterogenized MAO-free Metallocene Catalysts. Metalorganic catalysts for synthesis and polymerization. Kaminsky W, editor. Berlin: Springer; 1999.

[58] Atiqullah M, Nauman EB. A model and measurement technique for micromixing in copolymerization reactors. Chem Eng Sci 1990;45:1267-79.

[59] Atiqullah M. Imperfect/incomplete micromixing effects on copolymerization in a premixed-feed stirred tank reactor. Eur Polym Jour 1993;29:1581-8.
[60] Atiqullah M. Modeling and measurement of micromixing effects on bulk copolymerization in a stirred tank reactor, Troy, New York: Rensselaer Polytechnic Institute; 1988. PhD Thesis.

[61] Zurek E, Woo TK, Firman TK, Ziegler T. Modeling the dynamic equilibrium between oligomers of $\left(\mathrm{AlOCH}_{3}\right)_{\mathrm{n}}$ in methylaluminoxane (MAO). A theoretical study based on a combined quantum mechanical and statistical mechanical approach. Inorg Chem 2001:40:361-70.

[62] Zurek E, Ziegler T. A combined quantum mechanical and statistical mechanical study of the equilibrium of trimethylaluminum (TMA) and oligomers of $\left(\mathrm{AlOCH}_{3}\right)_{\mathrm{n}}$ found in methylaluminoxane (MAO) solution. Inorg Chem 2001;40:3279-92.

[63] Zurek EA. Theoretical Investigation of the Structure and Function of MAO, Canada: University of Calgary; 2002. MS Thesis.

[64] Zurek E, Ziegler T. Toward the identification of dormant and active species in MAO (Methylaluminoxane)-activated, dimethylzirconocene-catalyzed olefin polymerization. Organometallics 2002;21:83-92.

[65] Negureanu L, Hall RW, Butler LG, Simeral LA. Methyaluminoxane (MAO) polymerization mechanism and kinetic model from ab initio molecular dynamics and electronic structure calculations. J Am Chem Soc 2006;128:16816-26.

66] Ystenes M, Eilertsen JL, Jianke LIU, Matthias OH, Rytter E, Stovneng JA. Experimental and theoretical investigations of the structure of methylaluminoxane (MAO) cocatalysts for olefin polymerization. J Polym Sci Part A: Polym Chem 2000;38:3106-27.

67] Talsi EP, Semikolenova NV, Panchenko VN, Sobolev AP, Babushkin DE, Shubin AA Zakharov VA. The metallocene/methylaluminoxane catalysts formation: EPR spin probe study of Lewis acidic sites of methylaluminoxane. J Mol Catal A: Chem 1999;139:131-7

[68] Boudene Z, De Bruin T, Toulhoat H, Raybaud P. A QSPR Investigation of thermal stability of $\left[\mathrm{Al}\left(\mathrm{CH}_{3}\right) \mathrm{O}\right]_{\mathrm{n}}$ oligomers in methylaluminoxane solution: the Identification of a geometry-based description. Organometallics 2012;31:8312-22.

[69] Chaichana E, Khaubunsongserm S, Praserthdam P, Jongsomjit B. Ethylene-hexene copolymer derived from [t-butylfluorenylsilyl-amido] dimethyl titanium complex. Exp Polym Lett 2010;4:94-100

[70] Schaverien C], Ernst R, Schut P, Dall'Occo T. A new class of diastereomeric metallocenes for the copolymerization of $\alpha$-olefins. Organometallics 2001;20:343652.

[71] Sperling LH. Introduction to physical polymer science. New York: John Wiley; 2005.

[72] Subramaniam CP. Morphology, crystallization and melting behaviors of random copolymers of ethylene with 1-butene, 1-pentene and 1-hexene, Blacksburg, Varginia, USA: Virginia Polytechnic Institute and State University; 1999. PhD Thesis.

[73] Kotzabasakis V, Petzetakis N, Pitsikalis M, Hadjichristidis N, Lohse DJ. Copolymerization of tetradecene-1 and octene-1 with silyl-protected 10-undecen-1-ol using a $\mathrm{C}_{\mathrm{s}}$-symmetry hafnium metallocene catalyst. A route to functionalized $\operatorname{poly}(\alpha-$ olefins). J Polym Sci Part A: Polym Chem 2009;47:876-86.

[74] Zhou H, Wilkes GL. Comparison of lamellar thickness and its distribution determined from DSC, SAXS, TEM and AFM for high-density polyethylene films having a stacked lamellar morphology. Polymer 1997;38:5735-47.

[75] Chen F, Shanks RA, Amarasinghe G. Molecular distribution analysis of meltcrystallized ethylene copolymers. Polym Intl 2004;53:1795-805.

[76] Musa RK, Lijun F, Tao H. A generalized equation for the prediction of melting temperatures of homopolymers and copolymers. The Can J Chem Eng 2002;80:43242.

[77] Lijun F, Musa RK. Distributions of crystal size from DSC melting traces for polyethylenes. The Can J Chem Eng 2004;82:1239-51.

[78] Anton E, Adams TA, Arnaud R. Hydroperoxidation in the low-temperature thermooxidation of linear low density polyethylene. Polymer 1994;35:433-434.

[79] Richardson MJ, Flory PJ, Jackson JB. Crystallization and melting of copolymers of polymethylene. Polymer 1963;4:221-36.

[80] Pérez E, Vanderhart DL, Crist B, Howard PR. Morphological partitioning of ethyl branches in polyethylene by ${ }^{13} \mathrm{C}$ nuclear magnetic resonance. Macromolecules 1987;20:78-87.

[81] Hosoda S, Nomura H, Gotoh Y, Kihara H. Degree of branch inclusion into the lamellar crystal for various ethylene $/ \alpha$;-olefin copolymers. Polymer 1990;31:1999-2005.

[82] Hosoda S, Nozue Y, Kawashima Y, Utsumi S, Nagamatsu T, Wagener K, Berda E, Rojas G, Baughman T, Leonard J. Perfectly controlled lamella thickness and thickness distribution: a morphological study on ADMET polyolefins. Macromol Symp 2009;282:50-64. 